\title{
Multimodality imaging review of focal renal lesions
}

\author{
Jonathan Lyske ${ }^{1}$, Rishi Philip Mathew ${ }^{2^{*}}$ (D), Christopher Hutchinson ${ }^{1}$, Vimal Patel ${ }^{1}$ and Gavin Low ${ }^{1}$
}

\begin{abstract}
Background: Focal lesions of the kidney comprise a spectrum of entities that can be broadly classified as malignant tumors, benign tumors, and non-neoplastic lesions. Malignant tumors include renal cell carcinoma subtypes, urothelial carcinoma, lymphoma, post-transplant lymphoproliferative disease, metastases to the kidney, and rare malignant lesions. Benign tumors include angiomyolipoma (fat-rich and fat-poor) and oncocytoma. Nonneoplastic lesions include infective, inflammatory, and vascular entities. Anatomical variants can also mimic focal masses.

Main body of the abstract: A range of imaging modalities are available to facilitate characterization; ultrasound (US), contrast-enhanced ultrasound (CEUS), computed tomography (CT), magnetic resonance (MR) imaging, and positron emission tomography (PET), each with their own strengths and limitations. Renal lesions are being detected with increasing frequency due to escalating imaging volumes. Accurate diagnosis is central to guiding clinical management and determining prognosis. Certain lesions require intervention, whereas others may be managed conservatively or deemed clinically insignificant. Challenging cases often benefit from a multimodality imaging approach combining the morphology, enhancement and metabolic features.
\end{abstract}

Short conclusion: Knowledge of the relevant clinical details and key imaging features is crucial for accurate characterization and differentiation of renal lesions.

Keywords: Renal cell carcinoma, Lymphoma, Post-transplant lymphoproliferative disease, Renal metastases, Angiomyolipoma, Oncocytoma

\section{Background}

Focal lesions of the kidney, broadly classified as malignant tumors, benign tumors, and non-neoplastic lesions, are being detected with increasing frequency due to escalating imaging volumes. It is incumbent upon radiologists to be familiar with the imaging appearances of these lesions and the appropriate differential diagnoses. Accurate characterization is integral to guiding clinical management and determining prognosis. Some lesions require surgery, whereas others may be managed without intervention and followed up on imaging or classified as clinically insignificant. Utilizing a multimodality

\footnotetext{
* Correspondence: dr_rishimathew@yahoo.com

${ }^{2}$ Department of Radiology, Rajagiri Hospital, Chunangamvely, Aluva, Kochi, Kerala 683112, India

Full list of author information is available at the end of the article
}

imaging approach, ultrasound (US), contrast-enhanced ultrasound (CEUS), computed tomography (CT), magnetic resonance (MR) imaging, and positron emission tomography (PET), renal lesions can be characterized on the basis of morphology, enhancement, and metabolic features. In this article, we review focal renal lesions in terms of characteristic imaging features that facilitate a confident diagnosis and highlight potential pitfalls that may lead to diagnostic errors.

\section{Malignant tumors \\ Renal cell carcinoma \\ Renal cell carcinoma (RCC) is the most common adult epithelial cancer representing $90 \%$ of renal tumors [1]. RCC accounts for $4 \%$ of all new cancer cases and its in- cidence is increasing by $1-2 \%$ per annum. This is}


attributed to an increase in the volume of imaging studies performed $[2,3]$. RCC has a median age at diagnosis of 64 years and a male predilection. Several genetic conditions are associated with the development of RCCs, with von Hippel-Lindau disease the most prevalent. Environmental risk factors include smoking and obesity. RCC is classically described as presenting with the triad of flank pain, hematuria, and a flank mass; however, this only occurs in $5-10 \%$ of cases $[2,4]$. A substantial proportion of RCCs are discovered incidentally [5].

The World Health Organization (WHO) classification of tumors of the kidney describes multiple subtypes or RCC [6]. RCC has three main histological subtypes; clear cell, papillary, and chromophobe. Rare RCC subtypes include collecting duct and medullary carcinomas which comprise $<1 \%$ of all renal tumors. The subtypes have separate cytogenetic and immunohistochemical profiles with varying prognosis and response to treatment. Characterizing the RCC subtype on imaging has implications for clinical management $[1,6,7]$.

RCC is typically staged using the TMN system (Tables 1 and 2) [8].

\section{Clear cell RCC}

Clear cell tumor is the most common subtype accounting for $70 \%$ of RCCs [5]. This subtype has the greatest propensity to metastasize and the poorest prognosis with a 5-year survival of 44-69\% [5]. At gross pathology, clear cell RCC has a characteristic golden yellow color due to an abundance of lipid-rich cells [1].
Table 2 Staging groups for RCCs [8]

\begin{tabular}{llll}
\hline Stage & $\mathbf{T}$ & $\mathbf{M}$ & $\mathbf{N}$ \\
\hline I & T1 & N0 & M0 \\
II & T2 & No & M0 \\
II & T3 & N0 & M0 \\
IV & T1, T2 or T3 & N1 & M0 \\
& T4 & Any N & M0 \\
& Any T & Any N & M1 \\
\hline
\end{tabular}

\section{Papillary RCC}

Papillary tumors account for $10-15 \%$ of RCCs [5]. They are multifocal in $23 \%$ of cases and have a lower incidence of metastases and a more favorable prognosis with a 5year survival of $82-92 \%$ [9]. Papillary RCCs are pathologically divided into two groups; type 1 tumors have a single layer of small cells with a scanty cytoplasm and tend to have a lower Fuhrman grade. Type 2 tumors have large eosinophilic cells with pleomorphic nuclei and have a higher Fuhrman grade and a poorer prognosis [7].

\section{Chromophobe RCC}

Chromophobe tumors comprise 5\% of RCCs. They also have a more favorable outcome with a 5-year survival of 78-92\% [9]. Macroscopically, they are solid wellcircumscribed tumors with a light brown color. Histological characteristics include large polygonal cells with prominent cell membranes [9].

Imaging of RCC The imaging features of RCC encompass a wide spectrum from small indolent lesions to

Table 1 TMN staging for RCC [8]

\begin{tabular}{|c|c|}
\hline TMN stage & Disease extent \\
\hline $\mathrm{T1}$ & Tumor $\leq 7 \mathrm{~cm}$ and confined to the kidney \\
\hline$\cdot$ T1a & - Tumor $\leq 4 \mathrm{~cm}$ \\
\hline$\cdot \mathrm{T} 1 \mathrm{~b}$ & - Tumor $>4 \mathrm{~cm}$ but $\leq 7 \mathrm{~cm}$ \\
\hline $\mathrm{T} 2$ & Tumor $>7 \mathrm{~cm}$ and confined to the kidney \\
\hline$\cdot \mathrm{T} 2 \mathrm{a}$ & - Tumor $>7 \mathrm{~cm}$ but $\leq 10 \mathrm{~cm}$ \\
\hline$\cdot \mathrm{T} 2 \mathrm{~b}$ & - Tumor $>10 \mathrm{~cm}$ but confined to the kidney \\
\hline T3 & Tumor extension into major veins or perinephric tissues but not into ipsilateral adrenal gland or beyond Gerota's fascia \\
\hline$\cdot$ T3a & $\begin{array}{l}\text { - Tumor grossly extends into the renal vein or its segmental (muscle containing) or tumor invades perirenal and/or } \\
\text { renal sinus fat but not beyond Gerota's fascia }\end{array}$ \\
\hline$\cdot \mathrm{T} 3 \mathrm{~b}$ & - Tumor grossly extends into the vena cava below the diaphragm \\
\hline$\cdot \mathrm{T} 3 \mathrm{C}$ & - Tumor grossly extends into the vena cava above the diaphragm or invades the wall of the vena cava \\
\hline T4 & Tumor invades ipsilateral adrenal gland or extends through Gerota's fascia \\
\hline NO & No regional lymph node metastases \\
\hline N1 & Metastases to regional lymph nodes \\
\hline MO & No distant metastases \\
\hline M1 & Distant metastases \\
\hline
\end{tabular}


large infiltrative masses with distant spread. Several overlapping features occur with a varying frequency between subtypes including intralesional calcification, intralesional microscopic fat, bilaterality, and multifocality [9]. However, certain imaging features can assist in subtyping the lesions.

Clear cell RCCs often have a heterogeneous appearance on imaging due to necrotic, hemorrhagic, and cystic contents (Fig. 1). Doppler ultrasound shows internal vascularity while the solid component of the RCC is hypervascular on CT and MRI in the corticomedullary phase. In the nephrographic phase, the tumor demonstrates wash out, enhancing less than the adjacent renal parenchyma [10]. A large mass, retroperitoneal vascular collaterals, and renal vein thrombus (Fig. 2) suggest a high-grade tumor [7]. On MRI, clear cell RCCs demonstrate low T1 signal intensity, heterogeneous high T2 signal intensity, and are hypervascular on the corticomedullary phase. Intralesional microscopic fat may be demonstrated on chemical shift T1-weighted imaging in 60\% of clear cell RCCs [7]. The presence of macroscopic fat is very rare and tends only to occur with areas of calcification (Fig. 3) [11].

Papillary $R C C s$ are typically small $(<3 \mathrm{~cm})$ peripheral lesions that are well circumscribed and homogenous. They are usually hypovascular relative to normal renal parenchyma on the corticomedullary phase of contrastenhanced CT or MRI (Fig. 4) [5, 7]. Multi-phase CT can frequently demonstrate indeterminate enhancement (an increase of attenuation between 10 and $20 \mathrm{HU}$ ); further assessment with MRI or contrast-enhanced ultrasound (CEUS) is required in such instances [12]. CEUS uses gas microbubbles as a contrast medium and can demonstrate enhancement in lesions which were equivocal on CT [13].

Larger tumors $(>4 \mathrm{~cm})$ can have a heterogeneous appearance due to necrosis, hemorrhage, or calcification (Fig. 5). This subtype is the most likely to be bilateral and/or multifocal. A key imaging characteristic of papillary RCC on MRI is that the tumor shows low T2 signal intensity. This MRI feature is not specific as it can also be seen in fat poor angiomyolipoma (AML). Papillary RCCs rarely contain fat. They can demonstrate areas of signal loss on in phase $\mathrm{T} 1$ images relative to out of phase T1 images due to hemosiderin content. The cystic variety can display papillary projections with internal blood products [7].

Chromophobe RCCs often appear as large, wellcircumscribed homogeneous lesions [5]. Perinephric and vascular infiltration are rare. Contrast-enhanced CT and MR display relatively uniform enhancement in chromophobe RCCs although, in $30-40 \%$ of cases, a central stellate scar and spoke-wheel enhancement may be visualized (Fig. 6) [7, 14]. This appearance has also been reported in oncocytoma [9].

The role of PET-CT in primary RCC evaluation is limited as physiological tracer excretion by the kidney can mask the tumor. PET-CT has a more
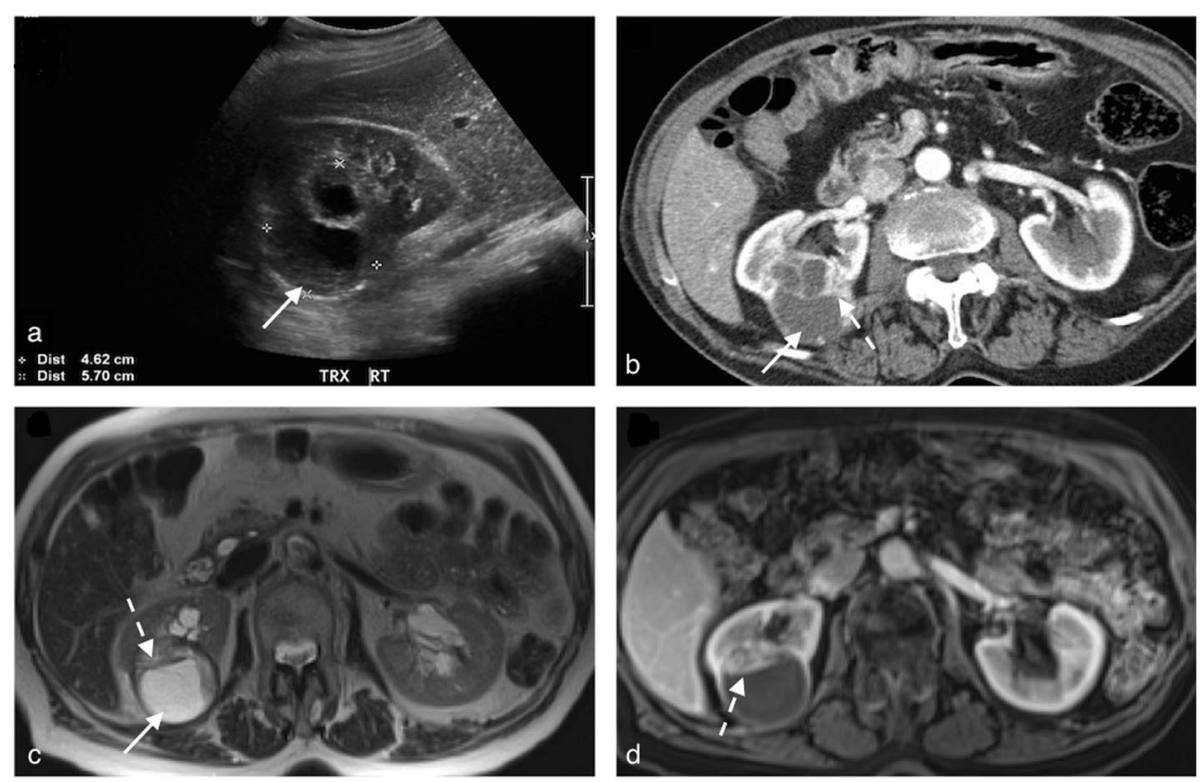

Fig. 1 Pathologically proved clear cell RCC in a 69-year-old man. a Transverse greyscale ultrasound image shows a right renal tumor with cystic and solid components (arrow). b Axial post contrast corticomedullary phase CT image shows the tumor is predominantly cystic (arrow) with internal septations and soft tissue (dashed arrow) which enhances similar to adjacent renal cortex. c Axial T2-weighted MR image shows the cystic (arrow) and heterogeneous solid (dashed arrow) components of the tumor. d Axial post contrast corticomedullary phase T1-weighted MR image shows tumoral enhancement of the solid component (dashed arrow) similar to the adjacent renal cortex 

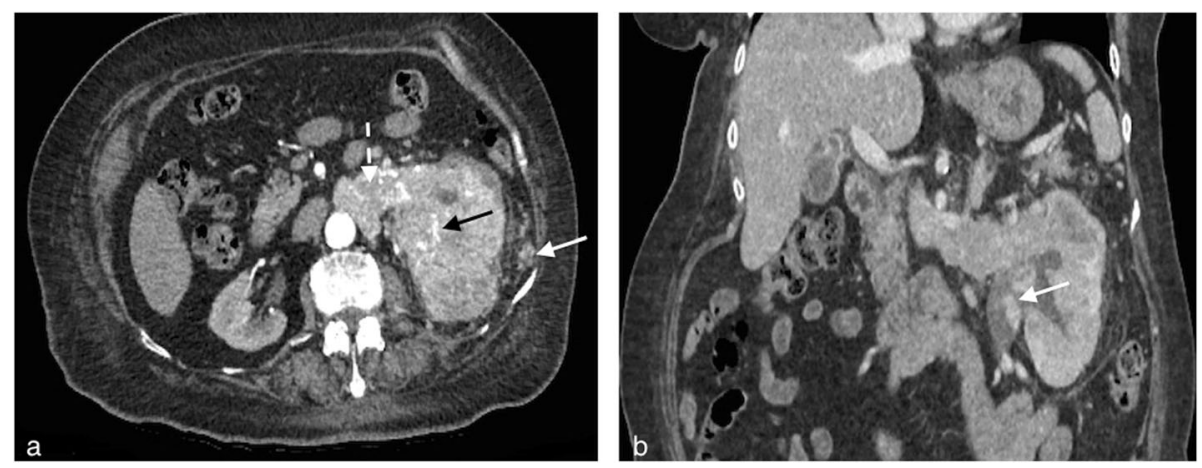

Fig. 2 A 77-year-old female presented with anemia secondary to an aggressive clear cell RCC. a Axial post contrast corticomedullary phase CT image shows a heterogeneous left renal tumor with increased vascularity (black arrow), invasion of the left renal vein (dashed arrow) and perinephric tumor deposits (white arrow). b Coronal post contrast nephrographic phase CT image shows tumor invasion of the collecting system (white arrow)

established role in re-staging advanced or recurrent RCC [9]. An emerging technique in nuclear medicine is single-photon emission computed tomography-CT (SPECT-CT) using indium-111-labelled-girentuximab. This isotope tracer recognises carbonic anhydrase IX, a specific antibody occurring in $94 \%$ of clear cell RCCs [15].

The principal differential diagnoses include AML, urothelial carcinoma (UC), oncocytoma, and lymphoma. Biopsy should be considered in instances where imaging findings are indeterminate. A biopsy can also confirm diagnosis prior to ablation and determine tumor histological grade and assist in prognostic assessment [16].

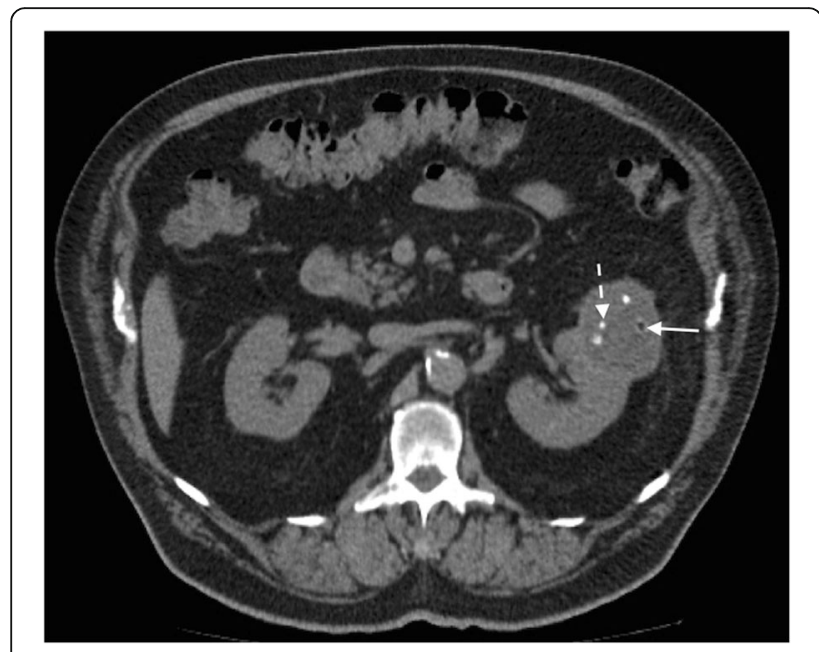

Fig. 3 Pathologically proven RCC containing calcification and macroscopic fat in an asymptomatic 73-year-old man. Axial unenhanced $C T$ shows a left renal tumor containing several foci of calcification (dashed arrow) and a focus of macroscopic fat (arrow)

\section{Pelvicalyceal urothelial carcinoma}

Upper urinary tract UC comprises $5-10 \%$ of all urothelial tumors. Specifically, UC of the renal pelvis is estimated to represent around $15 \%$ of all renal tumors. Concurrent bladder UC occurs in 17\% of cases of upper tract UC. Most upper tract UCs are superficial lowgrade tumors with around 15\% demonstrating infiltrative behavior [17]. Aggressive tumors can invade into the renal parenchyma without distorting the contour of the kidney. UC tends not to invade the renal veins or inferior vena cava. The incidence of upper tract UC peaks in the 7th decade and is three times more common in males than females. The principal risk factor is smoking. Upper tract UC often presents with hematuria or flank pain $[18,19]$.

Traditionally, excretory urography was used to detect upper tract UCs. Typical findings include a pelvicalyceal filling defect and a distended or amputated calyx due to an obstructing tumor in the infundibulum. An obstructing tumor at the ureteropelvic junction may result in hydronephrosis and poor contrast excretion. The upper tract can also be assessed during cystoscopy by a retrograde pyelogram. The imaging findings are similar to excretory urography but this technique has the advantage of facilitating cytological sampling [18, 19]. Ultrasound has limited sensitivity in detecting upper tract lesions. UC within the renal pelvis usually appears as a soft tissue mass within the echo bright renal sinus, with or without hydronephrosis. A tumor within the infundibulum may cause focal calyceal dilatation. Infiltrative UC may extend into the renal cortex where it typically appears slightly hyperechoic compared with the adjacent renal parenchyma $[18,19]$.

CT urography is the technique of choice. On the excretory phase, pelvicalyceal UC typically appears as a sessile filling defect, a mass lesion, or circumferential 

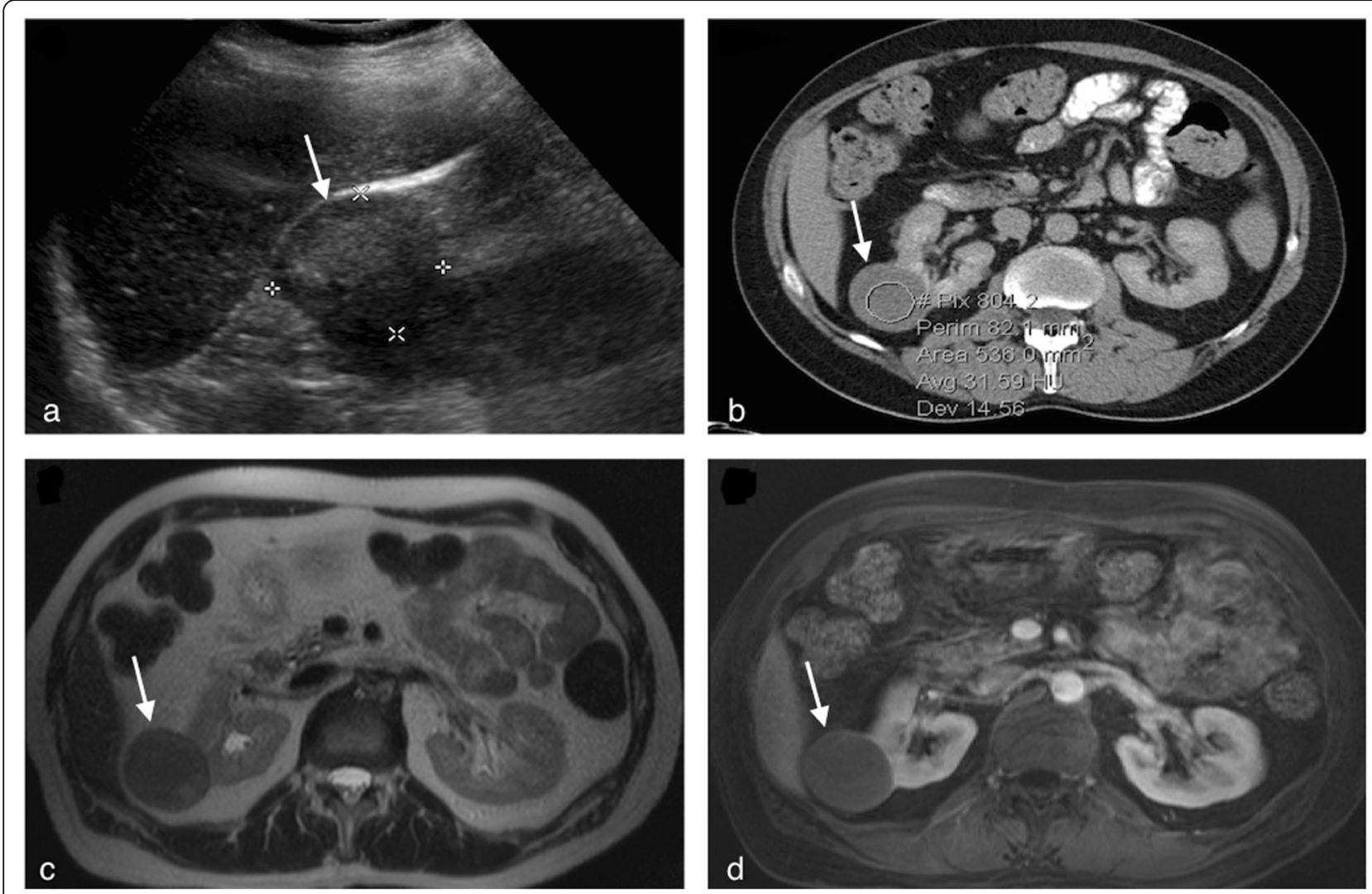

Fig. 4 A 66-year-old female with a pathologically proven papillary RCC (type1). a Longitudinal greyscale ultrasound image shows an exophytic homogeneous tumor (arrow) at the upper pole of the right kidney. $\mathbf{b}$ Axial post contrast nephrographic phase CT image shows the tumor (arrow) is homogeneous and hypovascular relative to the renal parenchyma. c Axial T2-weighted MR image shows the characteristic low signal of the tumor (arrow). d Axial post contrast corticomedullary phase T1-weighted MR image shows hypovascular nature of the tumor (arrow)

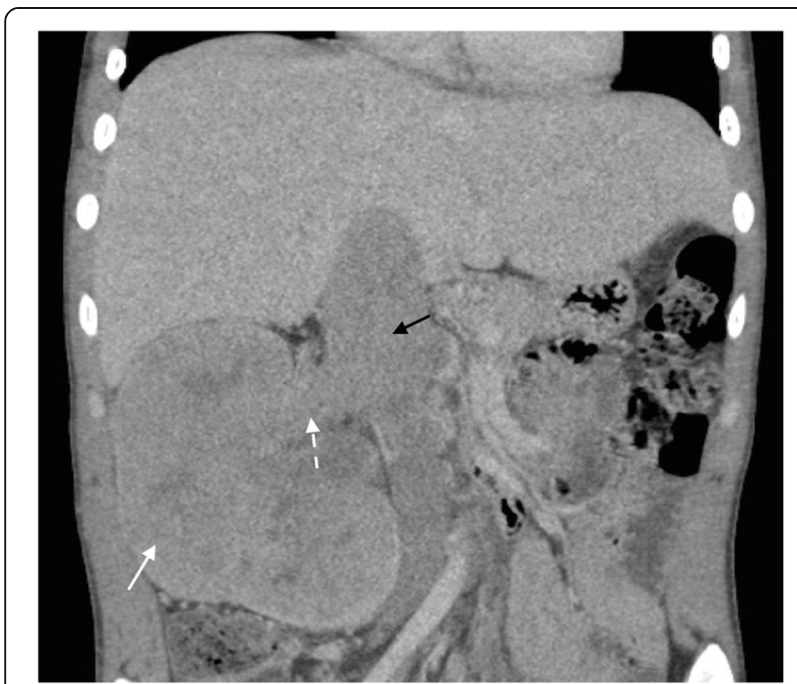

Fig. 5 Pathologically proven papillary RCC (type 2) in a 21-year-old male who presented with acute renal failure. Coronal post contrast nephrographic phase CT image shows a large heterogeneous hypovascular right renal tumor (white arrow) with tumor extension into the right renal vein (dashed arrow) and IVC (black arrow) wall thickening (Fig. 7). The nephrographic phase can complement the excretory phase, demonstrating the tumor as an enhancing soft-tissue mass against the background of the lower attenuation collecting system [20, 21]. Rarely, UC may contain tiny calcifications. An aggressive UC obliterating the sinus fat and infiltrating into the renal parenchyma may be seen as a hypoenhancing mass distorting the renal architecture with a resultant delayed nephrogram. This type of lesion is actually most reliably visualized on the corticomedullary phase. A large infiltrating pelvicalyceal UC can be difficult to differentiate from an RCC. Preservation of the reniform shape favors UC over RCC. Areas of necrosis may be seen in infiltrating UCs and it can be challenging to differentiate such a lesion from RCC, lymphoma, or xanthogranulomatous pyelonephritis (XGP) [21]. MR urography can be performed without intravenous contrast and may be helpful in evaluating UC in cases where contrast agents are contraindicated. Pre-contrast T1 sequences can be useful in excluding hemorrhage as a cause of a urothelial filling defect. Diffusion-weighted imaging (DWI) and apparent diffusion coefficient (ADC) maps have been shown to be useful in staging and predicting the 

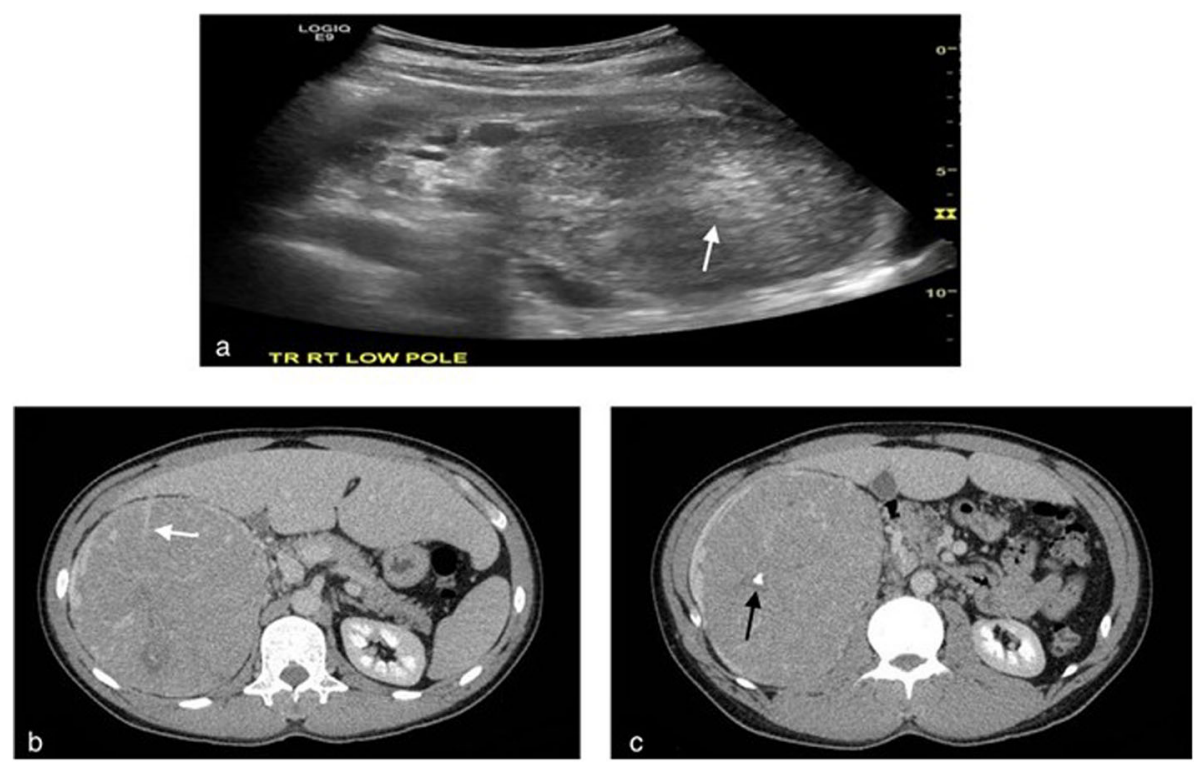

Fig. 6 A 39-year-old male with a pathologically proven chromophobe RCC presented with right flank pain. a Longitudinal greyscale ultrasound image shows a right lower pole mass with a central area of increased echogenicity representing a scar (white arrow). b, c Axial post contrast nephrographic phase CT images show a large mass with a spoke wheel enhancement pattern (white arrow) and a central scar containing a focus of calcification (black arrow)

histological grade of the tumor [22, 23]. Similar to RCC, the role of FDG PET-CT in upper tract UC diagnosis is limited as physiological tracer excretion by the kidney can mask the tumor. PET-CT can be used in staging advanced or recurrent UC [17].

Upper tract UC is typically staged using the TMN system (Tables 3 and 4) [24].

\section{Lymphoma}

Most cases of renal lymphoma occur as part of extensive disease affecting multiple solid organs or retroperitoneal nodes and is classified as secondary lymphoma. The histology is typically B cell non-Hodgkin's lymphoma (NHL). Primary renal lymphoma accounts for $<1 \%$ of extranodal NHL $[25,26]$. It is classified as isolated renal disease without associated mediastinal or pelvic adenopathy. Primary renal lymphoma occurs most frequently in middle-aged men and often presents with flank pain, weight loss, or fatigue [26].

Secondary renal lymphoma can present as single or multiple focal lesions in one or both kidneys. It may also arise in the perinephric region, the renal sinus, or cause nephromegaly.

The most common imaging manifestation of primary renal lymphoma is that of multiple renal masses, accounting for $40-60 \%$ of cases. Less common findings include direct extension to the kidneys from retroperitoneal adenopathy, diffuse renal involvement where the kidneys are enlarged but maintain their reniform shape, and a perinephric mass. In both types of renal lymphoma, the lesions are typically hypovascularthis feature may assist in differentiating lymphoma from other neoplasms that typically show greater enhancement. Renal lymphoma is usually a solid lesion that is hypoechoic relative to the renal parenchyma on ultrasound. CT typically demonstrates a homogenous lesion that shows minimal enhancement. The lesions may infiltrate the renal parenchyma or sinus with preservation of the reniform shape. A characteristic finding is the renal veins and arteries usually remain patent despite encasement. Retroperitoneal lymphadenopathy is common. Associated findings may include splenomegaly. On MRI, lymphomatous lesions are usually hypointense on T2weighted images and iso- to mildly hypointense on T1weighted images relative to the normal cortex (Fig. 8). Following contrast administration, the lesions enhance to a lesser degree than the adjacent normal cortex [25, 27]. The lesions show avid uptake of FDG on PET and have been shown to have a higher standardised uptake value compared to RCCs [28]. The main differential diagnoses include RCC, upper tract UC, and focal pyelonephritis. Percutaneous biopsy is typically required for diagnosis due to non-specific imaging findings [26].

\section{Post-transplant lymphoproliferative disease}

Post-transplant lymphoproliferative disease (PTLD) refers to a collection of lymphoproliferative diseases that develop after solid organ or stem cell transplantation $[25,29]$. The disease spectrum ranges from abnormal lymphoid hyperplasia to frank malignancy. The majority 

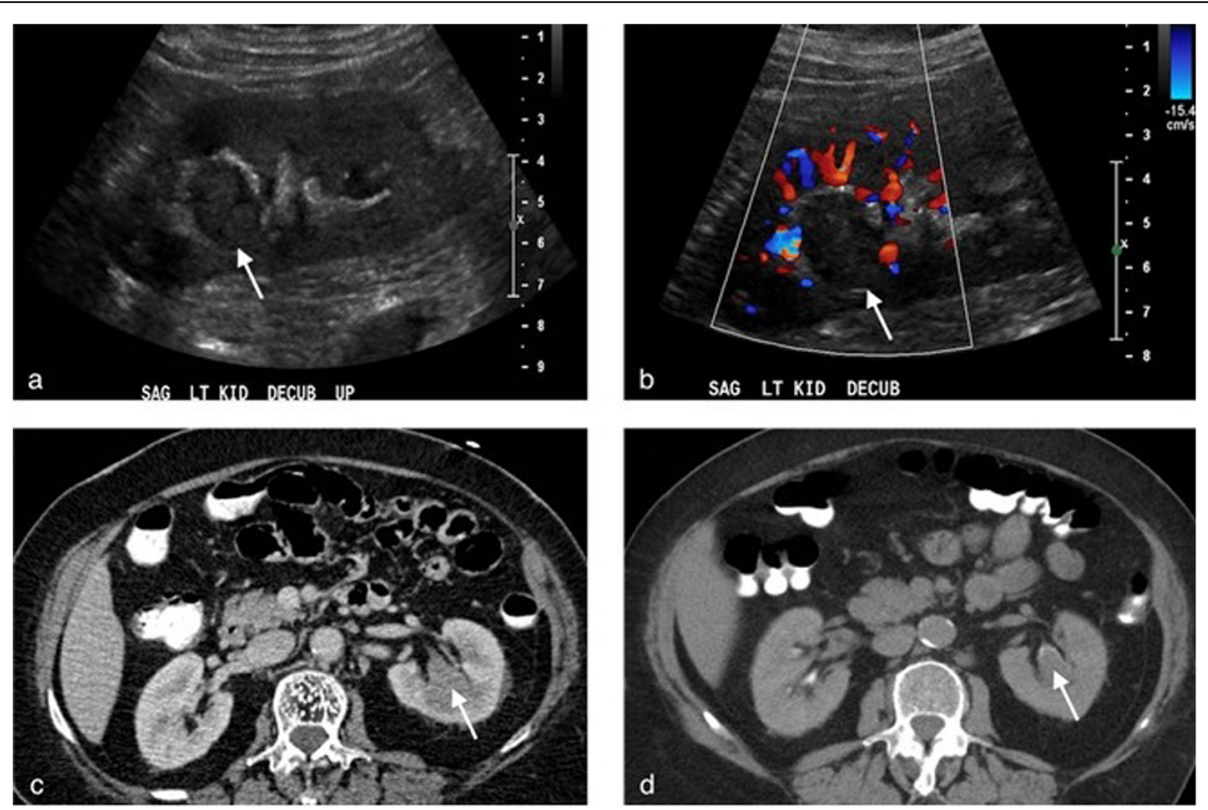

Fig. 7 Upper tract UC in a 69-year-old female patient. a Longitudinal greyscale ultrasound image shows a rounded soft tissue mass (arrow) in a dilated upper calyx in the left kidney. b Longitudinal greyscale with color Doppler ultrasound image shows the mass (arrow) is hypovascular. c Axial post contrast corticomedullary phase CT image shows the mass (arrow) is homogeneous and hypovascular relative to the renal parenchyma. $\mathbf{d}$ Axial post contrast excretory phase CT image confirms the mass (arrow) is within a calyx

of cases of PTLD are associated with proliferation of B lymphocytes due to Epstein-Barr virus infection. The incidence of PTLD ranges from 1 to $20 \%$ and is dependent on the transplanted organ. It develops in up to $20 \%$ of small bowel transplant recipients, $1-11 \%$ of heart transplant recipients, $2-10 \%$ of lung transplant recipients, $1-$ $3 \%$ of renal transplant recipients, and $1-3 \%$ of liver transplant recipients [30]. PTLD occurs most frequently in the first 12 months following transplantation and is more common in pediatric patients. PTLD can occur in any anatomical location but it is most common within the abdomen and is extranodal in $80 \%$. The three most common sites in the abdomen are the liver (50\%), small bowel (25\%), and kidneys (17\%) [26]. In renal transplant recipients, the allograft is the most frequently affected organ. PTLD can also occur in the native kidneys following transplantation of other organs. Treatment strategies include lowering the dose of immunosuppression, chemoradiation, or antiviral therapy. Despite treatment, the mortality is $30-60 \%$ [29].

Typical CT imaging findings in renal allograft PTLD include a heterogeneous hilar mass that may encase vessels or multiple hypovascular parenchymal lesions (Fig. 9). On MRI, these focal lesions are iso- to hypointense

Table 3 TMN staging for upper tract urothelial cancer [24]

\begin{tabular}{|c|c|}
\hline TNM stage & Disease extent \\
\hline$\overline{\mathrm{Ta}}$ & Noninvasive papillary carcinoma \\
\hline Tis & Carcinoma in situ \\
\hline $\mathrm{T} 1$ & Invasion of subepithelial connective tissue/lamina propria \\
\hline $\mathrm{T} 2$ & Invasion of muscularis propria \\
\hline T3 & Invasion of renal parenchyma \\
\hline T4 & Invasion of adjacent organs, the pelvic or abdominal wall or through the parenchyma into the perinephric fat \\
\hline No & No regional lymph node metastases \\
\hline N1 & Metastasis to a single node $<2 \mathrm{~cm}$ in greatest dimension \\
\hline N2 & Metastasis to a single node $2-5 \mathrm{~cm}$ in greatest dimension or multiple nodes $<5 \mathrm{~cm}$ in greatest dimension \\
\hline N3 & Metastasis to a node $>5 \mathrm{~cm}$ in greatest dimension \\
\hline MO & No distant metastasis \\
\hline M1 & Distant metastases \\
\hline
\end{tabular}


Table 4 Staging groups for upper tract urothelial cancer [24]

\begin{tabular}{llll}
\hline Stage & $\mathbf{T}$ & $\mathbf{N}$ & $\mathbf{M}$ \\
\hline 0 & Ta or Tis & N0 & M0 \\
I & T1 & N0 & M0 \\
II & T2 & N0 & M0 \\
III & T3 & N0 & M0 \\
IV & T4 & Any N & Any M \\
& Any T & N1, N2 or N3 & M0 or M1 \\
\hline
\end{tabular}

relative to the renal parenchyma on T1-weighted images and mildly hypointense on T2-weighted images. PTLD lesions tend to be FDG avid on PET. Diffuse infiltrative disease with nephromegaly has been described [25, 30]. PTLD should be considered in any new visceral lesion or lymphadenopathy in a transplant patient [29]. A biopsy may be required to confirm the diagnosis. The differential diagnoses include a new or recurrent malignancy and focal pyelonephritis.

\section{Metastases to the Kidney}

Isolated metastases to the kidney are rare. Typically, metastatic involvement of the kidneys occurs in diffuse dissemination of the primary malignancy. In these cases, the renal lesions tend to be multiple and bilateral. The most common primaries include the lungs followed by the breast, gastrointestinal tract, and melanoma [31, 32]. Studies have reported a wide range of time intervals between diagnosis of the primary tumor and detection of the renal metastases. One of the largest recent studies by $\mathrm{Wu}$ et al. reported a median interval of 3.1 years with a range of $<1$ year to $>20$ years [31]. Overall, it is difficult to establish patient prognosis from the limited number of small studies available [32, 33].

Metastases to the kidney tend to be encountered incidentally on imaging. Despite the absence of pathognomonic imaging features, there are several clues that suggest the diagnosis [33, 34]. Firstly, this involves being aware that there is a background history of cancer. The study by $\mathrm{Wu}$ at al. reported that in $88 \%$ of cases, there was a known history of primary cancer [31]. Secondly, metastases are typically hypovascular and endophytic on CT/MRI (Fig. 10) [34]. However, due to the low incidence of renal metastases and overlapping imaging features with other lesions such as RCC, a biopsy may ultimately be required [31].

\section{Benign tumors \\ Angiomyolipoma}

AML is the most frequently encountered solid benign renal tumor and is classified as a perivascular epithelioid cell tumor. AMLs contain variable amounts of dysmorphic blood vessels, smooth muscle cells, and adipose tissue. Recent recognition that renal AMLs comprise a heterogeneous group of lesions with a spectrum of pathological and radiological characteristics has led to the creation of a classification system by Jinzaki et al $[11,35]$. The majority of renal AMLs
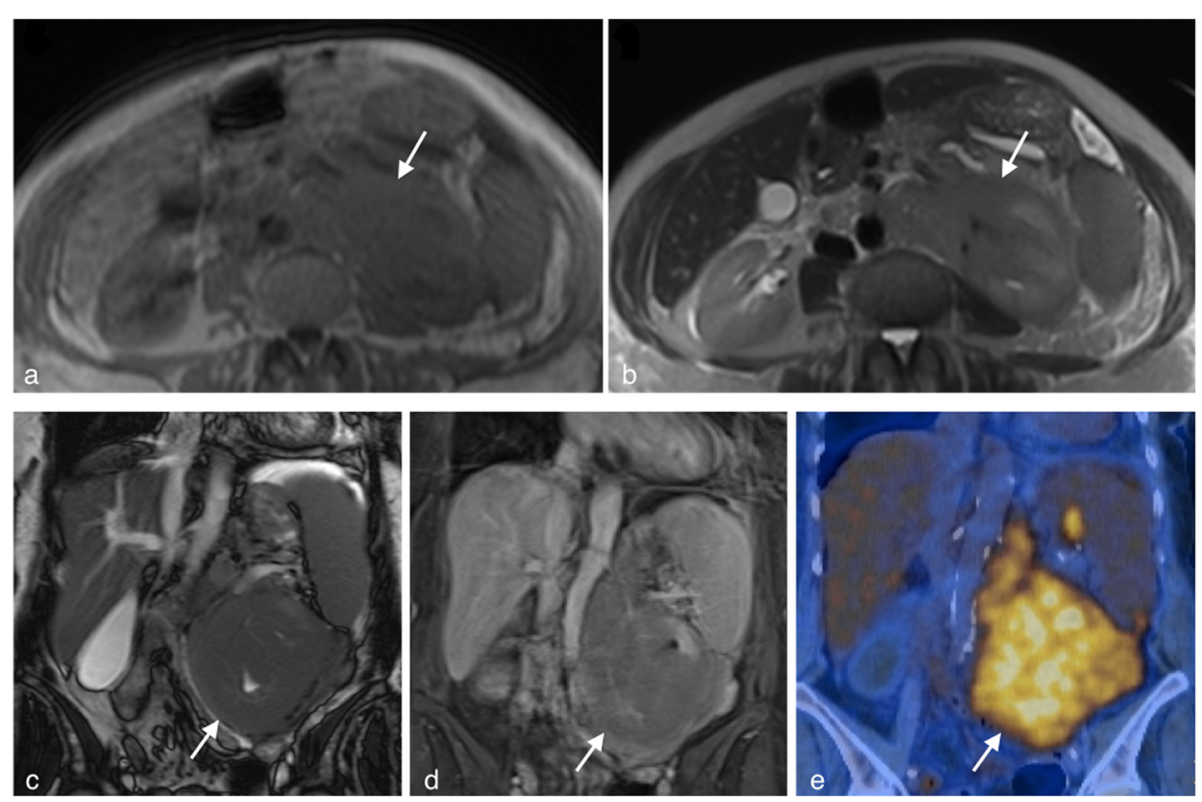

Fig. 8 Pathologically proven primary renal lymphoma in a 69-year-old man. a Axial T1-weighted, b axial T2-weighted, c coronal T2-weighted, and d postcontrast nephrographic phase T1-weighted MR images show a relatively homogeneous left lower pole renal mass which is mildly hypointense on T1- and T2-weighted images and hypovascular (arrow). e Coronal fused FDG PET/ CT image shows the mass is characteristically hypermetabolic with marked FDG uptake (arrow) 

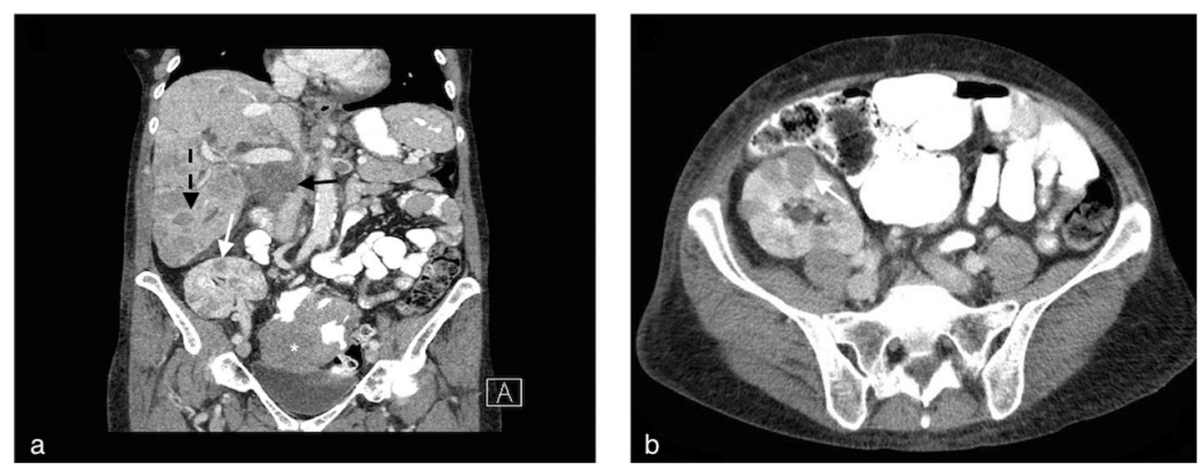

Fig. 9 A 51-year-old female with renal transplant PTLD presented with obstructive jaundice. a Coronal post contrast portal phase CT image shows multiple PTLD lesions in the right lower quadrant renal transplant (white arrow), liver (dashed arrow), and cecum (*). Periportal lymphadenopathy (black arrow) causes extrinsic compression of the common bile duct. $\mathbf{b}$ Axial post contrast portal phase $C T$ image shows the multiple hypovascular renal transplant PTLD lesions (white arrow)

occur sporadically. The remainder of AMLs is associated with syndromes such as tuberous sclerosis and lymphangioleiomyomatosis [36].

Based on imaging characteristics, benign AMLs can be split into classic (fat-rich) and fat-poor. The fat-poor AMLs can be subdivided into hyperattenuating AML, isoattenuating AML, and angiomyolipoma with epithelial cysts (AMLEC) [11]. Benign AMLs have an incidence rate of $<0.2 \%$ and occur most commonly in middle-aged females [34]. They tend to be discovered incidentally but can present with spontaneous hemorrhage particularly if $\geq 4 \mathrm{~cm}$ [37].

Classic AMLs are by far the most common subtype. Internal macroscopic fat is their characteristic feature. On ultrasound, they typically appear uniformly hyperechoic compared to normal renal parenchyma (Fig. 11). However, occasionally, an RCC can also appear uniformly hyperechoic and mimic an AML. Hypoattenuating regions $(<-10 \mathrm{HU})$ on unenhanced $\mathrm{CT}$ suggests macroscopic fat within an AML. Hemorrhage within an AML can mask the fat content. Contrast-enhanced CT is not usually required to diagnose a classic AML but is useful to demonstrate the vascular anatomy prior to embolization of large lesions. Macroscopic fat will appear hyperintense relative to the renal parenchyma on T1- and T2-weighted MR sequences and show signal loss on fat-suppressed sequences. In and out of phase imaging creates an India ink artifact at the interface between fat and soft tissue or fluid. This interface will appear at the border between the AML and renal parenchyma or within the lesion between fat and nonfatty components. Internal signal loss on opposed-phase T1 images compared to in-phase T1 images indicates the presence of microscopic fat-this may be seen in both AMLs and RCCs. The main differential diagnosis for a classic AML includes retroperitoneal liposarcoma and RCC. An exophytic AML will typically demonstrate a small defect in the renal cortex ("claw" sign) and a feeding vessel to the underlying kidney-this allows differentiation from a liposarcoma rarely contain fat cells originating in the kidney. Classic AMLs are differentiated from RCCs by macroscopic fat. Although RCCs can rarely contain macroscopic fat, it is often associated with calcifications [11, 35].

Hyperattenuating AMLs are a fat-poor subtype and comprises $5 \%$ of all AMLs. On ultrasound, it is generally
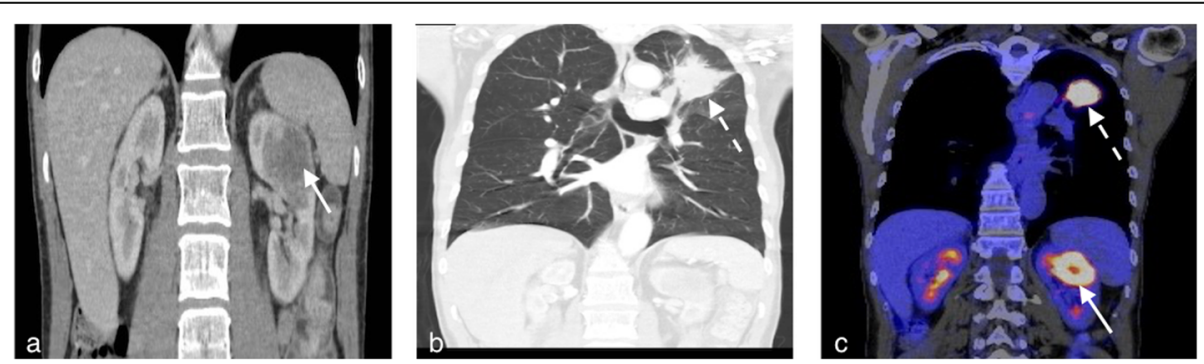

Fig. 10 A 68-year-old man with non-small cell lung cancer and a pathologically proven solitary metastasis to the left kidney. a Coronal post contrast nephrographic phase $C T$ image shows an endophytic hypovascular metastasis in the upper pole of the left kidney (arrow). b Coronal post contrast arterial phase CT image on lung windows shows the primary left upper lobe lung tumor (dashed arrow). c Coronal fused FDG PET/ CT image shows the lung tumor (dashed arrow) and renal metastasis (arrow) are both hypermetabolic with marked FDG uptake 

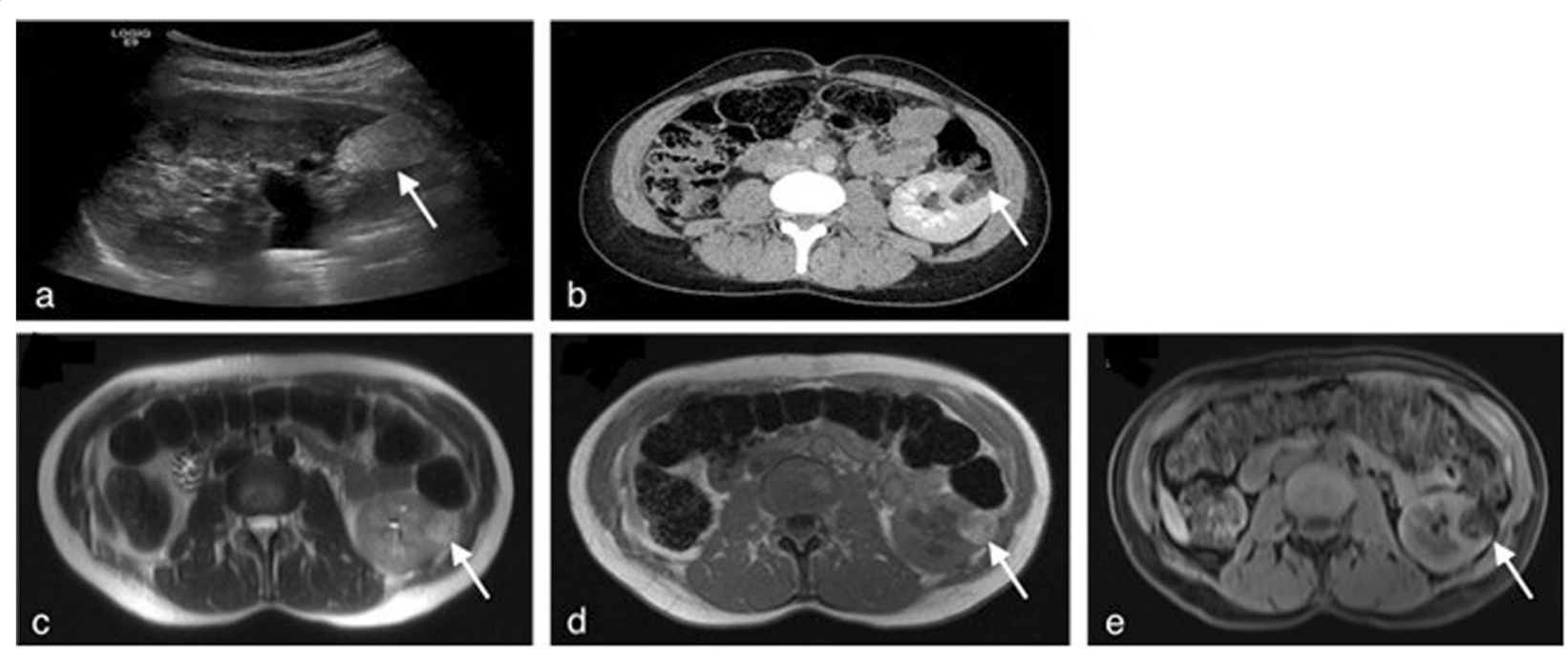

Fig. 11 A 37-year-old female with a classic left renal AML and right nephrectomy performed in childhood. a Longitudinal greyscale ultrasound image shows a hyperechoic lower pole AML (arrow). b Axial post contrast corticomedullary phase CT image shows macroscopic fat within the AML (arrow). c, d Axial T2- and T1-weighted MR images show hyperintense signal of the fat within the AML (arrow). e Axial fat-suppressed T1weighted MR image shows signal intensity loss of the macroscopic fat within the AML (arrow)

uniformly isoechoic relative to muscle. On unenhanced $\mathrm{CT}$, these lesions are usually small and hyperattenuating compared to renal parenchyma. They tend to enhance homogenously and avidly on CT and MRI. Hyperattenuating AMLs are hypointense on T1- and T2-weighted sequences and they generally do not demonstrate any signal loss on fat-suppressed and out of phase T1weighted sequences. Both fat-poor AMLs and papillary RCCs show low T2 signal intensity. If the lesion enhances homogeneously, then a hyperattenuating AML should be considered (Fig. 12). A biopsy is recommended to confirm the diagnosis $[11,35]$.

The isoattenuating AML fat-poor subtype is rare. These lesions are of a similar attenuation to renal parenchyma on unenhanced CT. MR features include hypointensity on T2-weighted images and signal loss on out of phase T1-weighted images compared to inphase images. This subtype cannot be reliably distinguished from clear cell RCC on imaging $[11,35]$.

AMLEC is the least common fat-poor subtype. It can be potentially malignant or overtly malignant. Imaging features include a hyperattenuating lesion on unenhanced CT and hypointense regions or septations with hyperintense cystic components on T2weighted images. A biopsy is required for definitive diagnosis [11, 35].

\section{Oncocytoma}

Oncocytoma is the second most common benign tumor comprising $3-7 \%$ of renal neoplasms. It has a peak incidence in the 7 th decade and a slight male predominance
[38, 39]. On histopathology, oncocytoma classically demonstrates nests and tubular structures lined with eosinophilic granular cytoplasm. However, variations in these features result in considerable overlap with chromophobe RCCs [40]. Oncocytoma and chromophobe RCCs also share common findings at gross pathology and imaging. Oncocytomas are often clinically silent but can present with pain or hematuria $[39,41]$.

Imaging findings can be variable due to the spectrum of cellular patterns that can influence tumor enhancement. Features suggestive, but not pathognomonic, of an oncocytoma includes a solid well-defined lesion with a central stellate scar (Fig. 13) and spoke wheel enhancement as well as segmental enhancement inversion [9, 42]. This latter finding represents two different areas of intralesional enhancement on the arterial phase that displays corresponding enhancement reversal on the excretory phase on CT/MRI [43]. Rare features include calcification, hemorrhage, cystic foci, and aggressive behavior [38]. Recent studies using sestamibi single-photon emission CT to distinguish between oncocytoma and RCC have shown promising results, although further studies are required $[44,45]$. As a result of the absence of pathognomonic imaging characteristics, a biopsy is often performed. However, pathological assessment of a core biopsy can be problematic as the sample may not be representative of the entire lesion [19]. In instances where the biopsy is suggestive of an oncocytoma but surgery is declined, active surveillance should be considered to avoid missing an RCC [38]. 

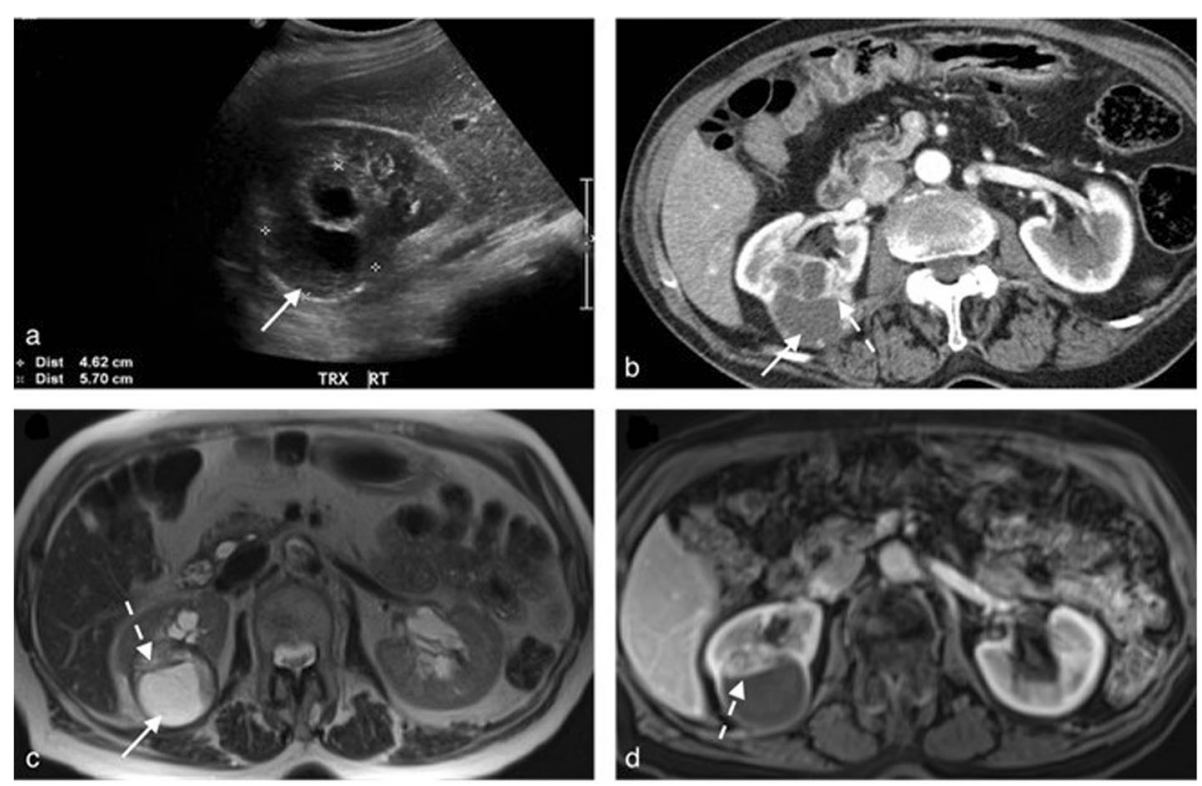

Fig. 12 A 46-year-old female with a fat poor right renal angiomyolipoma, biopsy was performed to confirm after MRI. a Axial T1-weighted MR image shows a hypointense fat poor AML (arrow). b Axial opposed phase T1-weighted MR image shows the AML does not contain any micro- or macroscopic fat (arrow). c Axial T2-weighted image shows the fat poor AML is hypointense (arrow). d Axial post contrast corticomedullary phase T1-weighted MR image shows hyperenhancement of the AML (arrow), allowing differentiation from a papillary RCC

\section{Non-neoplastic lesions}

\section{Infection}

Acute bacterial pyelonephritis typically results from ascending migration of an infectious bladder organism. The diagnosis is often made clinically based on symptoms, blood tests, and urinalysis. Imaging is not required in mild cases but is crucial in cases where the diagnosis is not clear or in patients with complicating factors such as immunosuppression or where there is a failure to respond to therapy [46].

Sonographic abnormalities include focal or generalized renal enlargement, focal changes in renal parenchymal echogenicity, reduced corticomedullary differentiation, and focal areas of reduced Doppler flow. However, in early disease, the kidneys can appear normal on US.
Contrast-enhanced CT is the modality of choice for detecting pyelonephritis-this may manifest as a wedgeshaped or rounded region of reduced or streaky enhancement with adjacent perinephric inflammatory change (Fig. 14) [46]. A striated nephrogram may also be seen. Occasionally, pyelonephritis can appear as a rounded lesion that displays mass effect. Such cases can be challenging to distinguish from a neoplasm.

Intraparenchymal or perinephric abscesses may develop as a complication of pyelonephritis. Abscess formation should be suspected in cases where appropriate antibiotics have not resulted in clinical improvement, particularly if the patient is immunosuppressed. Sonographic features include a fluid collection with internal debris and septations. On CT, renal abscesses are usually round areas of
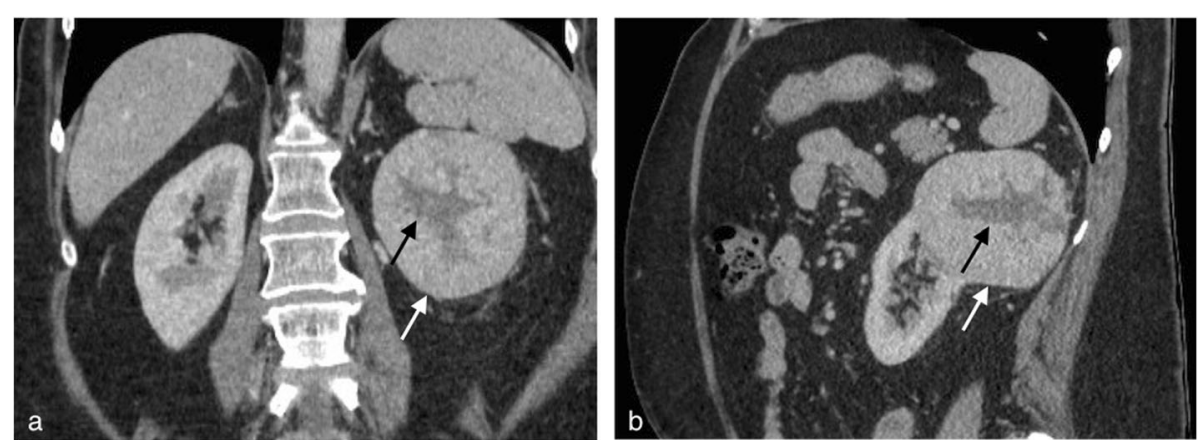

Fig. 13 A 62-year-old female with a pathologically proven renal oncocytoma. a Axial and $\mathbf{b}$ sagittal post contrast nephrographic phase CT images show a central stellate scar (black arrow) within a left renal oncocytoma (white arrow), this finding is not pathognomonic 


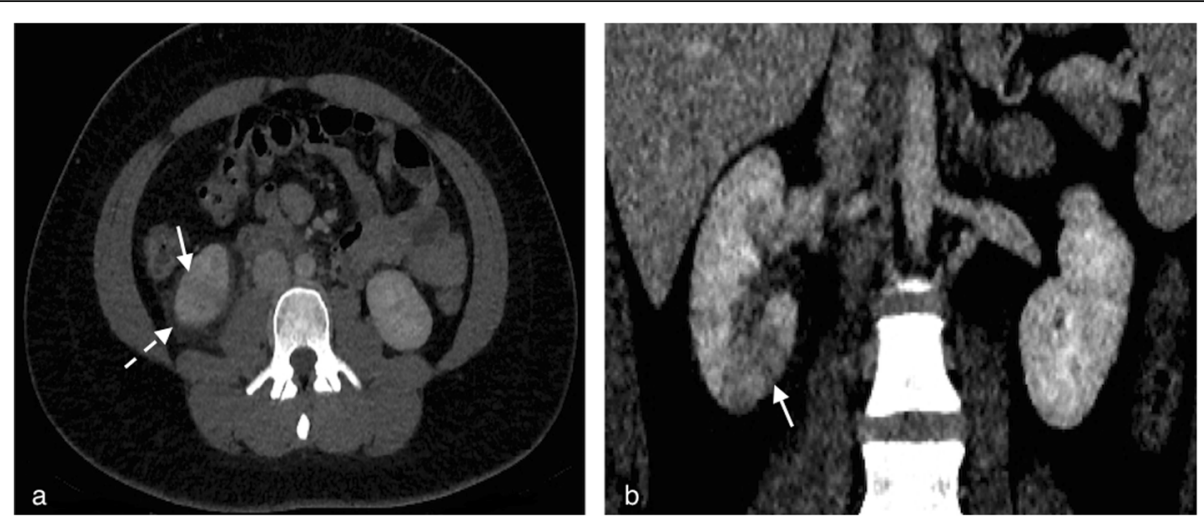

Fig. 14 Right pyelonephritis in a 23-year-old female with a 1-day history of right-sided abdominal pain, fever, and elevated inflammatory markers. a Axial post contrast nephrographic phase $\mathrm{CT}$ image with a narrow window shows reduced attenuation (arrow) at the lower pole of the right kidney with perinephric inflammatory fat stranding (dashed arrow). b Coronal post contrast nephrographic phase CT image with a narrow window shows a striated nephrogram at the lower pole of the right kidney (arrow)

low attenuation with an enhancing rim and adjacent inflammatory stranding (Fig. 15). Internal gas may be present. MRI findings are similar to CT with the internal contents demonstrating fluid signal characteristics and rim enhancement following gadolinium $[46,47]$.

XGP is induced by chronic renal obstruction and infection resulting in parenchymal destruction and replacement with lipid-laden macrophages. The most common pathogens are Escherichia coli and Proteus mirabilis. The condition typically occurs in immunocompromised middle-aged females. Symptoms are frequently non-specific $[48,49]$. Typical imaging findings across modalities include renal enlargement and a large obstructing staghorn calculus. XGP can rarely occur as a focal lesion and can be challenging to differentiate from a neoplasm. CT is the most useful modality in confirming the diagnosis and can facilitate surgical planning. Typical CT findings include a renal pelvis contracted around a staghorn calculus, caliectasis, inflammatory changes in the kidney, and fibrofatty proliferation in the surrounding tissues (Fig. 16) [49].
Immunocompromised patients are vulnerable to opportunistic infections, such as Mycobacterium and fungal infections. Renal tuberculosis (TB) causes papillary necrosis and parenchymal destruction. CT findings include caliectasis, strictures of the renal pelvis/infundibula, and calcifications [50]. Common fungal organisms include Candida and Aspergillus. On imaging, these infections can manifest as renal abscesses or hydronephrosis with filling defects in the dilated pelvicalyceal system. Microbiological tests are required to confirm the diagnosis $[46,51]$.

\section{Inflammatory}

\section{Sarcoid}

Sarcoidosis is a multisystem disorder characterized pathologically by the presence of non-caseating granulomas. Sarcoidosis has a female predominance and a peak incidence at 20-39 years of age. It is roughly three times more prevalent in Americans of African descent compared with Caucasian Americans. Around 90\% of patients have thoracic manifestations and approximately
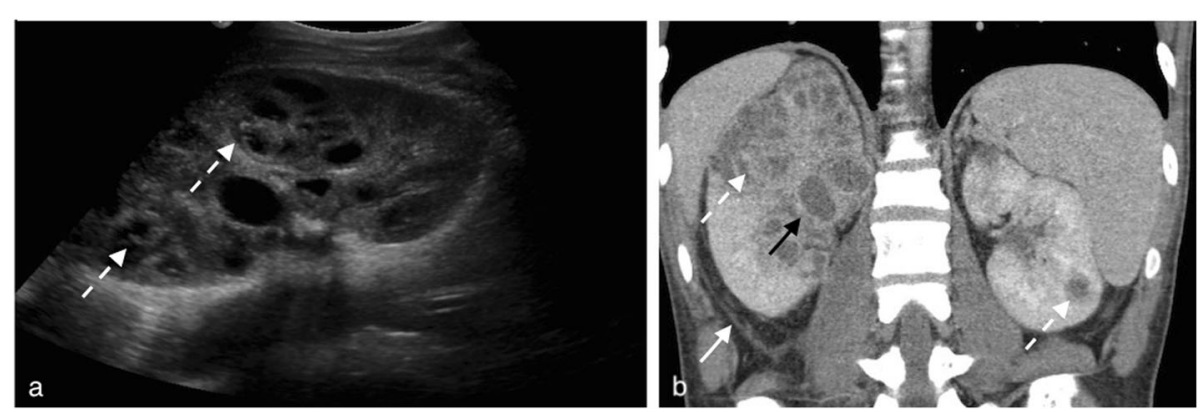

Fig. 15 Renal abscesses in an immunosuppressed 21-year-old man. a Longitudinal greyscale ultrasound image of the right kidney shows multiple intraparenchymal abscesses of varying complexity (dashed arrows). b Coronal post contrast nephrographic phase CT image shows multiple bilateral renal abscesses (dashed arrows), worse on the right, and perinephric inflammatory fat stranding (white arrow). The right renal abscesses show peripheral enhancement (black arrow) 

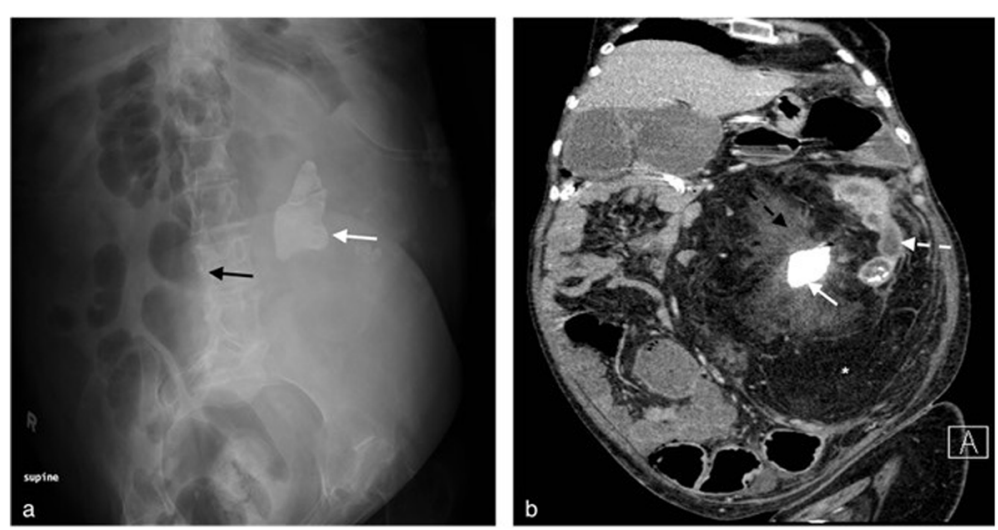

Fig. 16 XGP in a 67-year-old female who presented with left flank pain. a A supine abdominal radiograph shows a large left renal pelvis calculus (white arrow) and left abdominal mass which displaces bowel to the right (black arrow). b Coronal post contrast nephrographic phase CT image shows a renal pelvis contracted around a staghorn calculus (white arrow), caliectasis (dashed white arrow), inflammatory changes in the kidney (dashed black arrow), and fibrofatty proliferation in the surrounding tissues $\left({ }^{*}\right.$ )

$30 \%$ have extra-pulmonary disease [52, 53]. Renal sarcoidosis may present clinically with signs of altered calcium metabolism-this includes nephrocalcinosis, hypercalcemia, and hypercalciuria. Renal impairment can occur due to interstitial nephritis. Granulomatous involvement of the kidney can also be asymptomatic [54, 55]. Renal granulomas have been reported in $22 \%$ of sarcoid patients at autopsy but radiologically distinct granulomas are uncommon [52].

Granulomatous deposits within kidneys are often referred to as pseudotumors. These lesions can be single or multiple and have varied imaging appearances. Hypoechoic and hyperechoic lesions have both been reported on US $[52,56]$. On CT, the masses may be hypo-, iso-, or hyperattenuating relative to the renal parenchyma. Following contrast administration, they may or may not demonstrate enhancement. Renal sarcoidosis causing interstitial nephritis can produce a striated nephrogram on contrast-enhanced CT. MRI depicts pseudotumors as homogenous or heterogeneous lesions that are hypovascular on postcontrast images [53, 57]. On PET imaging using 18F-fluorodeoxyglucose, the renal granulomas have been reported to demonstrate avid tracer uptake. Due to the non-specific imaging appearance of renal sarcoid, it cannot be distinguished from other infiltrative renal masses. The presence of typical features of sarcoid in the chest may place it higher in the list of differential diagnoses but biopsy is needed for definitive diagnosis $[53,57]$.

\section{IgG4-related kidney disease}

IgG4-related kidney disease is a relatively newly recognized condition. This autoimmune disease affects a variety of organs, the pancreas being the most common [58]. Histopathologically, it is characterized by the presence of a dense lymphoplasmacytic infiltrate with an abundance of IgG4-positive plasma cells and fibrosis [59]. IgG4-related kidney disease most frequently occurs in middle-aged or elderly patients and has a predilection for males. The condition typically occurs in conjunction with other organ involvement. In the early stages, the patient may be asymptomatic. Advanced IgG4-related kidney disease can cause renal failure secondary to tubulointerstitial nephritis followed by glomerular disease. Urinalysis may show proteinuria. Serum IgG4 levels are frequently elevated $[58,60]$.

IgG4-related kidney disease can arise with the renal parenchyma (round or wedge-shaped lesions), renal pelvis, or perinephric region reference [61]. Generalized renal enlargement has also been described. The renal parenchyma is the most common location and lesions can appear as single or multiple nodules or diffuse patchy infiltrative lesions. Ultrasound findings tend to be non-specific. Sonographic features include poorly defined regions of reduced echogenicity and there may be irregularity of the renal contour. CT demonstrates rounded or wedge-shaped hypoenhancing lesions [58, 60]. On MRI, the lesions show low signal on T1- and T2-weighted images and display mild enhancement. DWI sequences have been shown to be helpful in detecting subclinical lesions [61, 62]. Renal pelvis or perinephric lesions are much less common. The presence of extra-renal disease and serum IgG4 levels can help clinch the diagnosis [60].

\section{Vascular and hemorrhagic lesions Renal infarction}

Renal infarction results from impaired arterial supply or venous drainage. Common causes include thromboembolic disease, renal artery abnormalities (dissection, aneurysm, and fibromuscular dysplasia), trauma, or 
vasculitis [63, 64]. Acute renal infarction can rarely present with flank pain or hematuria. It is usually detected incidentally on imaging [64].

Contrast-enhanced CT is the first-choice imaging modality for detecting renal infarction. Typical findings are one or more wedge-shaped regions of hypoattenuation (denoting non-enhancement) involving the cortex and medulla (Fig. 17). More diffuse infarcts may display mass effect. In these cases, the presence of a thin rim of cortical enhancement (cortical rim sign) adjacent to the hypoattenuating renal parenchyma is virtually pathognomonic for an infarct. A flip-flop enhancement pattern has also been described where the region of reduced attenuation demonstrates delayed enhancement on later phases. This feature can be helpful in differentiating an infarct from a tumor. It is also crucial to assess other organs for the presence of additional infarcts and the vasculature for a potential causative etiology [64, 65]. In patients with contraindications for intravenous contrast, an alternative modality is CEUS. This technique has been shown to have comparable accuracy to CT. Renal infarction appears as a wedge-shaped region of nonperfusion on CEUS [66].

\section{Renal artery aneurysm}

Renal artery aneurysms have a prevalence of $0.01-1 \%$ [67]. They are frequently saccular and are more common in females. Fibromuscular dysplasia and atherosclerosis are the most common etiological factors. Patients typically present in the sixth decade of life usually as an incidental discovery on imaging. A small proportion of patients present with symptoms due to rupture or from thromboembolic disease [68]. The majority of renal artery aneurysms arise at the main renal artery division. Around $10 \%$ occur within the renal parenchyma and can mimic solid or cystic renal lesions on imaging. Any anechoic lesion in the renal sinus should be assessed with color-Doppler to rule out an aneurysm. Ultrasound with color Doppler characteristically shows turbulent flow with communication to the renal artery. The presence of thrombus or calcification within the aneurysm may result in undetectable Doppler signal (Fig. 18). In such instances, evaluation with CT and/or MRI should provide definitive characterization $[67,69]$.

\section{Benign hyperattenuating cysts}

Benign cysts containing hemorrhage or proteinaceous content are responsible for the vast majority of hyperattenuating renal lesions. Key imaging features include small size $(\leq 3 \mathrm{~cm})$, clearly defined margins with at least one quarter abutting perinephric fat, homogenous hyperattenuation, and absence of enhancement (on CT an increase in attenuation by $10 \mathrm{HU}$ following contrast). An increase in attenuation $\geq 20 \mathrm{HU}$ is considered enhancement while an increase of 10-20 HU is considered indeterminate. Beam hardening and partial volume averaging on contrast-enhanced CT can present a potential pitfall through pseudoenhacement, i.e., an artificial increase in attenuation [70, 71]. The recent White Paper by the ACR on the management of the incidental renal mass on CT stated that a homogenous mass of $\geq 70 \mathrm{HU}$ on unenhanced CT is almost always a hyperdense Bosniak II cyst and requires no further evaluation [70]. However, a lesion of the same attenuation detected on contrast-enhanced CT is indeterminate and should be characterized further with a multiphase CT or MRI. A heterogenous hyperattenuating lesion also requires multiphase imaging for characterization. MRI is the imaging modality of choice and can detect internal hemorrhage or proteinaceous material due to their $\mathrm{T} 1$ hyperintensity (Fig. 19) [70, 72]. Post gadolinium subtraction sequences are useful for differentiating a renal neoplasm with secondary intratumoral hemorrhage from a simple hemorrhagic or proteinaceous renal cyst [73]. CEUS can also be used to assess for intralesional enhancement [66].

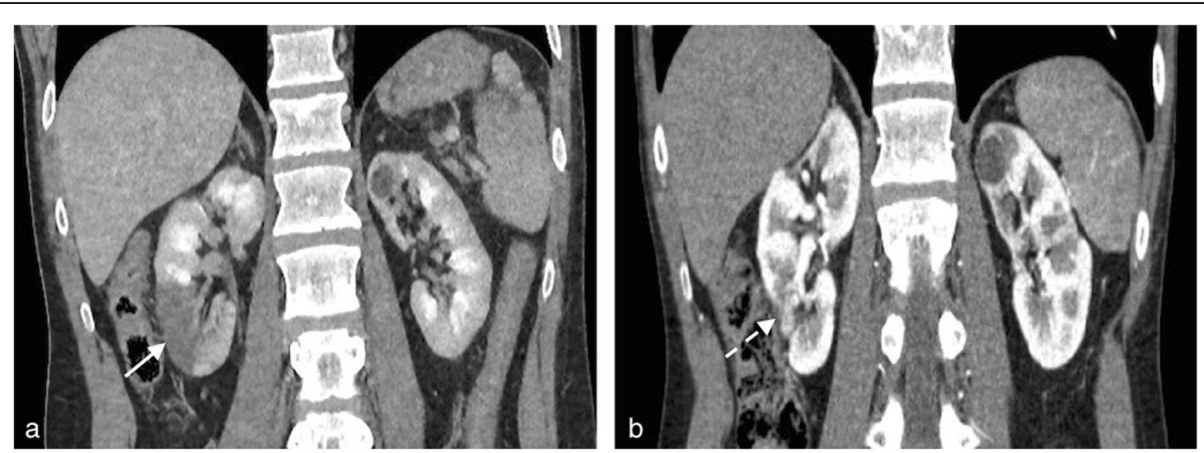

Fig. 17 A 34-year-old male with a right renal infarct and a past medical history of polyarteritis nodosa presented with right upper quadrant pain. a Coronal post contrast corticomedullary phase CT shows a wedge-shaped area of infarct in the lower pole of the right kidney (arrow). b Coronal post contrast corticomedullary phase CT performed 18 months after (a) shows a cortical defect at the site of the infarct (dashed arrow) 

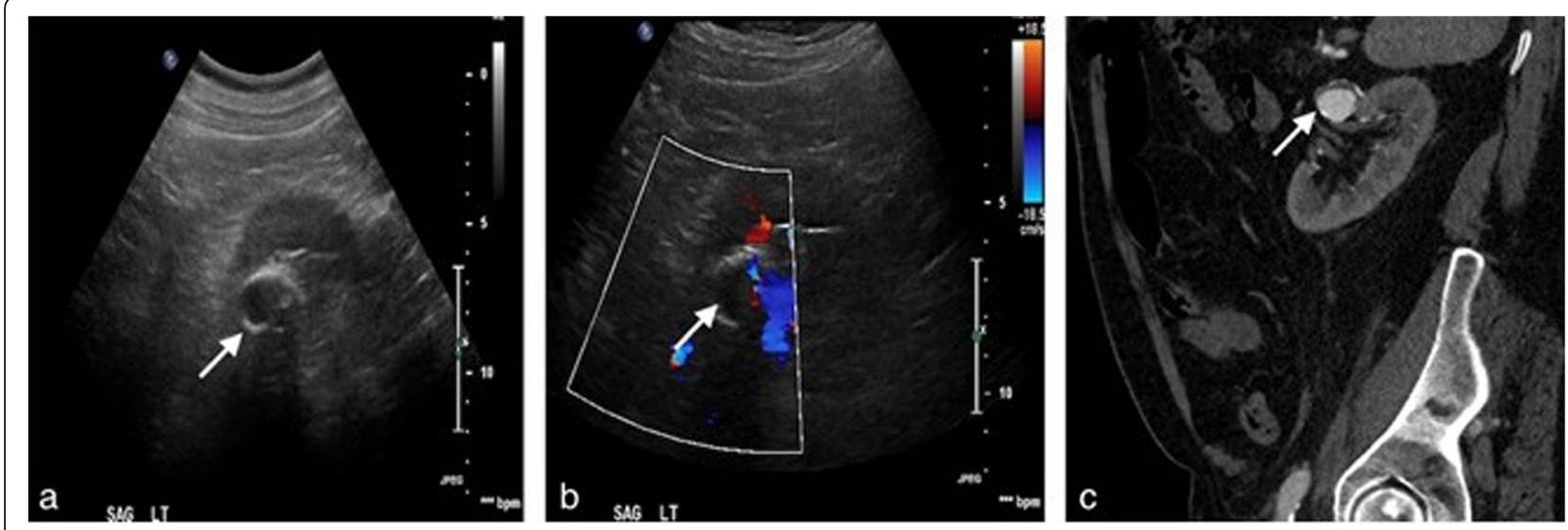

Fig. 18 Renal artery aneurysm mimicking a renal lesion in an asymptomatic 68-year-old female. a Transverse greyscale ultrasound image shows a rounded lesion with mural calcification in the left kidney (arrow). b Transverse greyscale ultrasound with color Doppler image shows no vascular flow within the lesion (arrow). c Sagittal post contrast corticomedullary phase CT image confirms the lesion is a renal artery aneurysm with mural calcification and atherosclerosis (arrow)

\section{Anatomical variants}

A prominent column of Bertin is an anatomical variant that can mimic a mass. It results from hypertrophied cortical tissue. This pseudomass typically occurs between upper and interpolar calyces and is more common on the left. On contrast-enhanced CT and MRI, the enhancement pattern in a column of Bertin should be identical to the renal cortex on all phases-this is most evident on the corticomedullary phase (Fig. 20). The absence of cortical disruption allows differentiation from RCC $[74,75]$.

A dromedary hump is another anatomical variant that can be mistaken for a mass. It is due to the splenic impression and appears as a focal bulge on the superolateral portion of the left kidney. Similar to a prominent column of Bertin, the enhancement pattern should match that of the adjacent renal cortex on all post contrast phases (Fig. 21) [74, 76].

\section{Small renal mass in clinical practice}

Detection of an incidental small renal mass $(\leq 4 \mathrm{~cm})$ on imaging is a common situation for a radiologist. The lesion will either be completely characterized or it will be indeterminate. These indeterminate lesions will typically go on to have a multiphase CT or MRI unless there are benign features such as previous imaging showing stability over at least 5 years [70,77]. Were image findings are consistent with localized RCC, there are a variety treatment options available depending on the patient profile. For instance, young patients will typically be offered a nephrectomy or nephron-sparing surgery, whereas patients with a limited life expectancy or significant comorbidity could be considered for active surveillance or percutaneous ablation [70, 78]. In cases which remain indeterminate following a multiphase CT or MRI, further workup options include percutaneous biopsy or alternative imagining techniques [77].

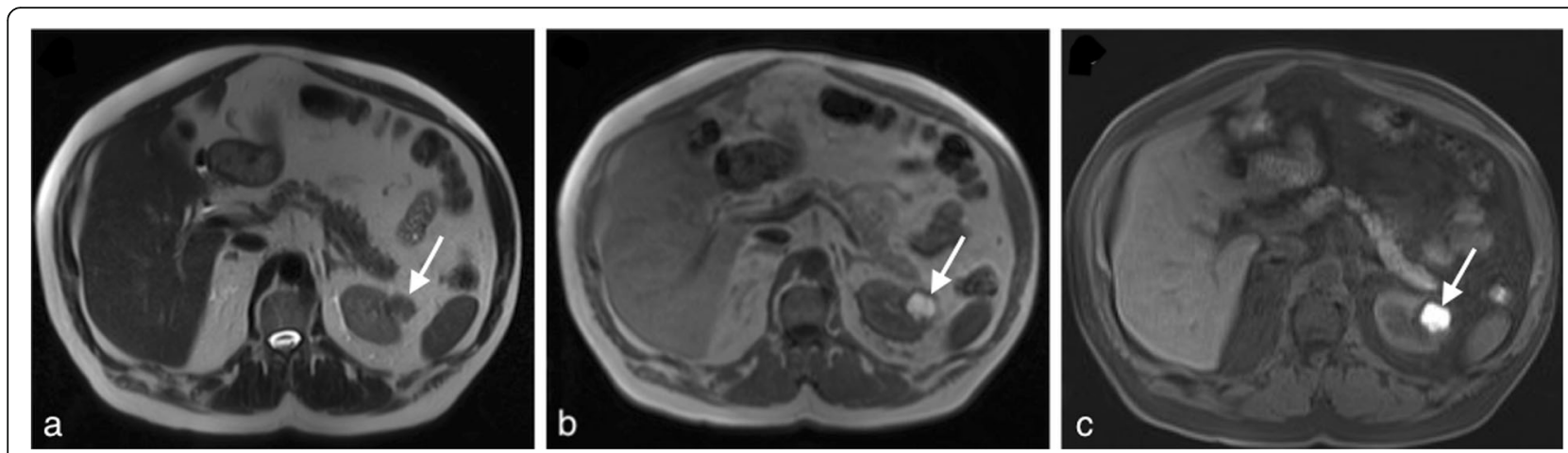

Fig. 19 Left hemorrhagic/proteinaceous renal cyst in an asymptomatic 68-year-old female. a Axial T2-weighted MR image shows a partially exophytic hypointense left renal lesion (arrow). b Axial T1-weighted MR image shows hyperintense signal within the lesion (arrow). c Axial T1weighted with fat subtraction MR image shows no signal loss within the lesion suggesting internal hemorrhagic/proteinaceous material (arrow). No internal enhancement on the post contrast subtraction images confirming the benign nature of the lesion 

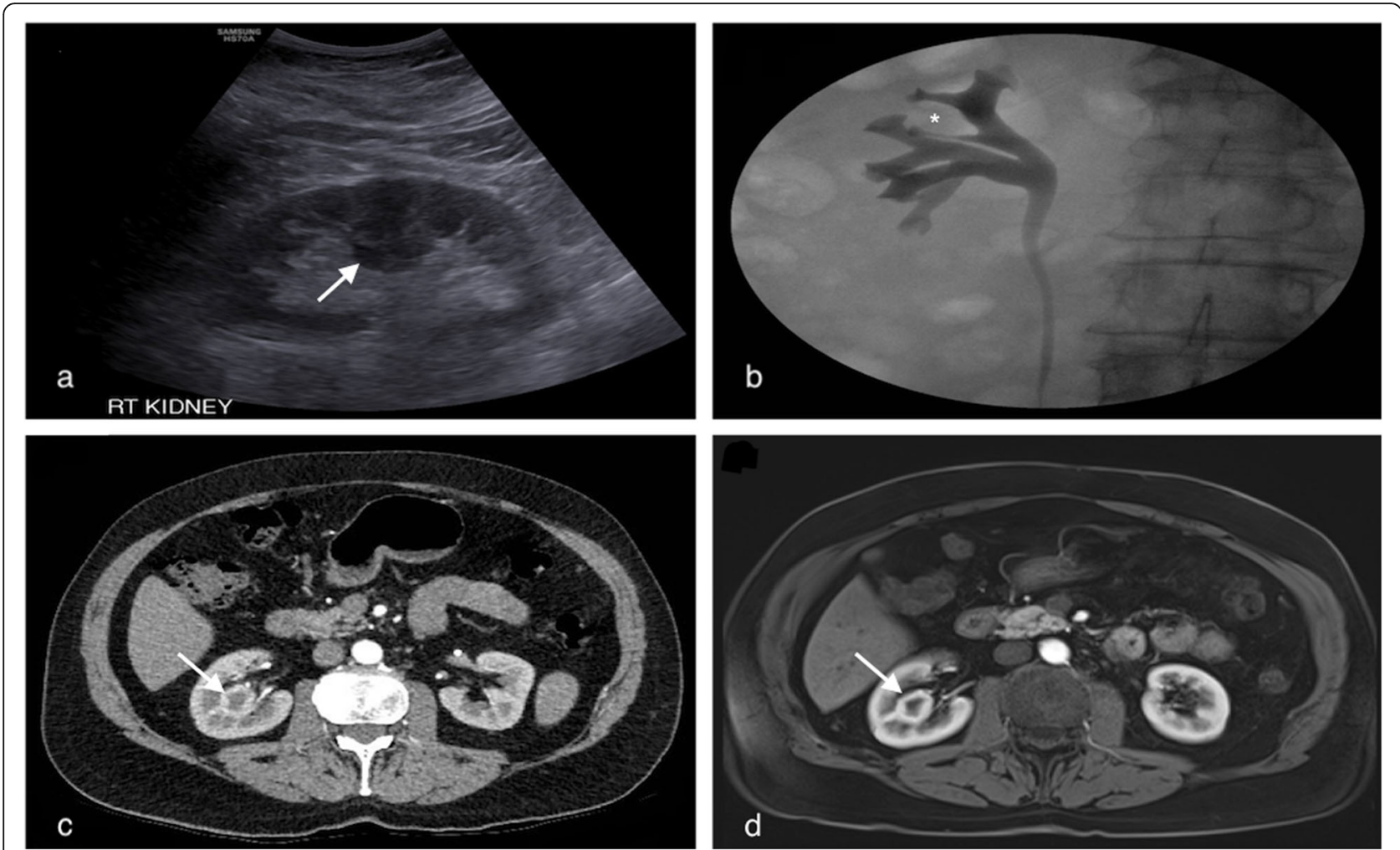

Fig. 20 Prominent column of Bertin incidentally detected on a 62-year-old male with symptoms of urinary tract obstruction. a Longitudinal greyscale ultrasound image shows hypertrophied cortical tissue in the interpolar region of the right kidney (arrow). b Retrograde pyelogram image shows splaying and narrowing of upper polar/interpolar calyces secondary to the hypertrophied cortical tissue $\left(^{*}\right)$. c Axial post contrast corticomedullary phase $C T$ and $\mathbf{d}$ MRI images show the enhancement pattern of the prominent column of Bertin is identical to the renal cortex (arrow)

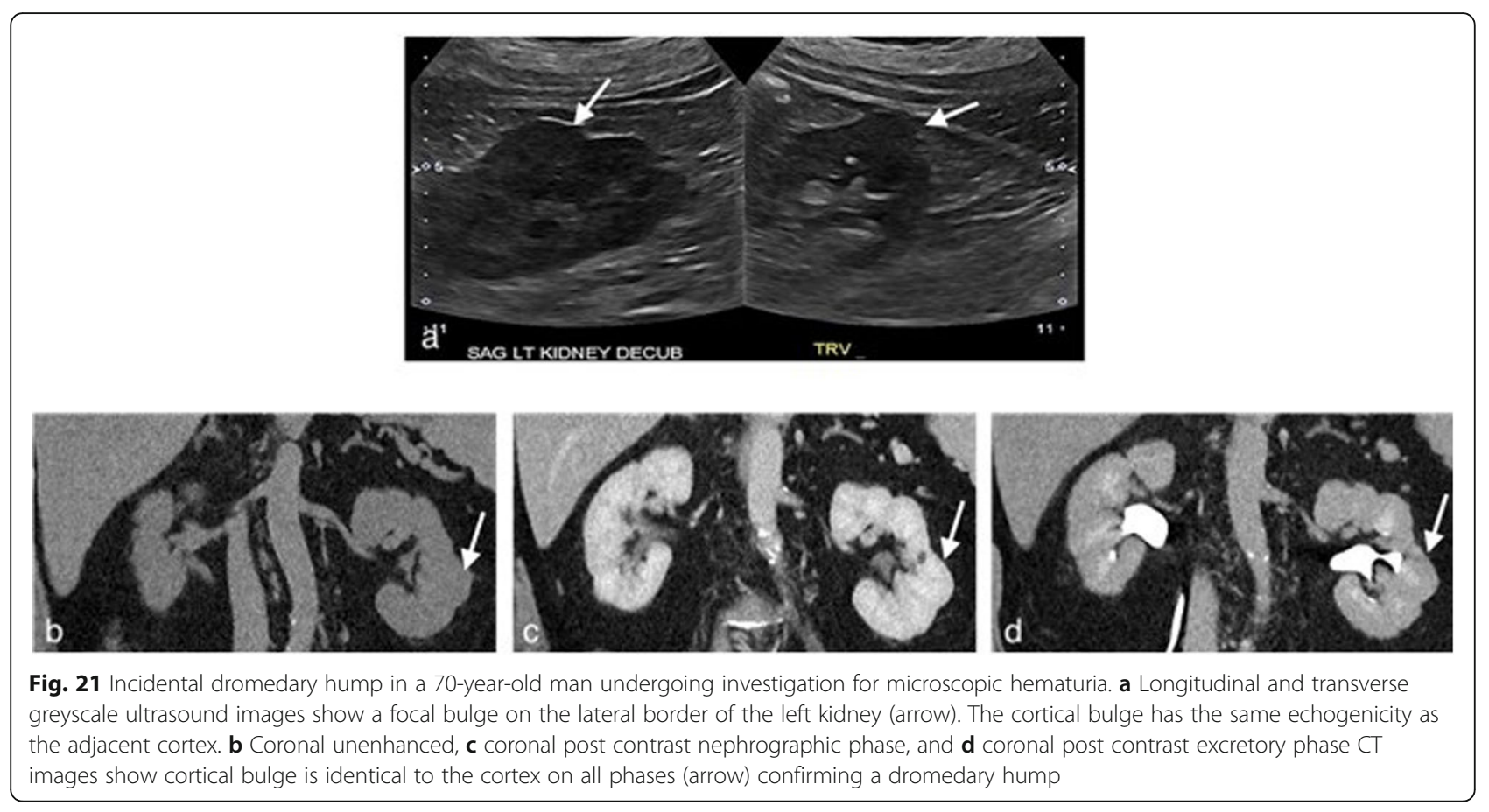




\section{Renal mass biopsy}

Percutaneous renal mass biopsy is a safe procedure with a high diagnostic yield. It has a crucial role in the work up of indeterminate renal lesions and assisting clinical decisions in the following scenarios; patients with a renal mass and an extra-renal malignancy to distinguish between separate primaries and a metastasis to the kidney, patients with likely metastatic/unresectable renal malignancy to allow sub typing for potential systemic therapy, patients with a small renal mass $(\leq 4 \mathrm{~cm})$ which may be suitable for active surveillance or minimally invasive treatments, and patients with multiple/bilateral renal masses who may have an underlying hereditary condition $[77,79]$.

\section{Alternative imaging techniques}

CEUS using intravenous microbubbles allows dynamic assessment of microvasculature. It can therefore assist differentiation between cystic and solid lesions and characterization of complex cystic lesions. It is a useful tool in patients who have contraindications for iodinated contrast or MRI [77].

Dual energy CT can create virtual non-contrast images from a single-phase contrast-enhanced scan. It is particularly helpful with incidental lesions detected on a single-phase post contrast CT were the virtual noncontrast images can differentiate between a soft tissue tumor and a hyper dense cyst without requiring a repeat multiphase CT [77, 80].

Tc-99m sestamibi single-photon emission computed tomography (SPECT)/CT has shown promise in a number of studies at differentiating oncocytoma and RCC, with oncocytoma demonstrating positive tracer uptake and RCC being negative [81].

\section{Conclusion}

Focal lesions of the kidney can be caused by a range of malignant tumors, benign tumors, and non-neoplastic entities. Lesions can have overlapping radiological features requiring a multimodality imaging approach. Knowledge of relevant clinical details and key imaging features is crucial for accurate characterization and differentiation.

\footnotetext{
Abbreviations

AML: Angiomyolipoma; AMLEC: Angiomyolipoma with epithelial cysts; CEUS: Contrast-enhanced ultrasound; CT: Computed tomography; MRI: Magnetic resonance imaging; PET: Positron emission tomography; PTLD: Post-transplant lymphoproliferative disorder; RCC: Renal cell carcinoma; RT: Renal tuberculosis; SPECT-CT: Single-photon emission computed tomography-CT; UC: Urothelial carcinoma; US: Ultrasound; WHO: World Health Organization; XGP: Xanthogranulomatous pyelonephritis
}

\section{Authors' contributions}

JL: design and concept, manuscript preparation, and review of literature; RPM: literature search and manuscript preparation; $\mathrm{CH}$ : literature search and manuscript editing; VP: manuscript editing and manuscript review; GL: manuscript review and Guarantor. All authors have read and approved the manuscript.

\section{Funding}

None.

Availability of data and materials

Not applicable.

Ethics approval and consent to participate

Not applicable.

Consent for publication

Not applicable.

\section{Competing interests}

The authors declare that they have no competing interests.

\section{Author details}

${ }^{1}$ Department of Radiology \& Diagnostic Imaging, Faculty of Medicine and Dentistry, University of Alberta, 8440112 St NW, Edmonton, AB T6G 2B7, Canada. ${ }^{2}$ Department of Radiology, Rajagiri Hospital, Chunangamvely, Aluva, Kochi, Kerala 683112, India.

Received: 17 August 2020 Accepted: 14 December 2020

Published online: 05 January 2021

\section{References}

1. Cupido BD, Sam M, Winters SD et al (2017) A practical imaging classification for the non-invasive differentiation of renal cell carcinoma into its main subtypes. Abdom Radiol (NY) 42(3):908-917. https://doi.org/10.1007/s00261016-0940-3 [published Online First: 2016/10/16]

2. Motzer RJ, Jonasch E, Agarwal N et al (2017) Kidney cancer, Version 2.2017, NCCN Clinical Practice Guidelines in Oncology. J Natl Compr Canc Netw 15(6):804-834. https://doi.org/10.6004/jnccn.2017.0100 [published Online First: 2017/06/10]

3. Motzer RJ, Agarwal N, Beard C et al (2011) Kidney cancer. J Natl Compr Canc Netw 9(9):960-977 [published Online First: 2011/09/16]

4. Ng CS, Wood CG, Silverman PM et al (2008) Renal cell carcinoma: diagnosis, staging, and surveillance. AJR Am J Roentgenol 191(4):1220-1232. https:// doi.org/10.2214/AJR.07.3568 [published Online First: 2008/09/23]

5. Prasad SR, Humphrey PA, Catena JR et al (2006) Common and uncommon histologic subtypes of renal cell carcinoma: imaging spectrum with pathologic correlation. Radiographics 26(6):1795-1806. https://doi.org/10. 1148/rg.266065010 discussion 806-10. [published Online First: 2006/11/15]

6. Moch H, Cubilla AL, Humphrey PA et al (2016) The 2016 WHO classification of tumours of the urinary system and male genital organs-part a: renal, penile, and testicular tumours. Eur Urol 70(1):93-105. https://doi.org/10. 1016/j.eururo.2016.02.029 [published Online First: 2016/03/05]

7. Lopes Vendrami C, Parada Villavicencio C, DeJulio TJ et al (2017) Differentiation of solid renal Tumors with Multiparametric MR Imaging. Radiographics 37(7):2026-2042. https://doi.org/10.1148/rg.2017170039 [published Online First: 2017/11/14]

8. American Joint Committee on Cancer (2017) Ch. 60 - Kidney. In: AJCC Cancer Staging Manual, 8th edn. Springer, New York

9. Low G, Huang G, Fu W et al (2016) Review of renal cell carcinoma and its common subtypes in radiology. World J Radiol 8(5):484-500. https://doi.org/ 10.4329/wjr.v8.i5.484 [published Online First: 2016/06/02]

10. Birnbaum BA, Jacobs JE, Ramchandani P (1996) Multiphasic renal CT: comparison of renal mass enhancement during the corticomedullary and nephrographic phases. Radiology 200(3):753-758. https://doi.org/10.1148/ radiology.200.3.8756927 [published Online First: 1996/09/01]

11. Jinzaki M, Silverman SG, Akita $\mathrm{H}$ et al (2017) Diagnosis of renal angiomyolipomas: classic, fat-poor, and epithelioid types. Semin Ultrasound CT MR 38(1):37-46. https://doi.org/10.1053/j.sult.2016.11.001 [published Online First: 2017/02/27] 
12. Krishna S, Murray CA, McInnes MD et al (2017) CT imaging of solid renal masses: pitfalls and solutions. Clin Radiol 72(9):708-721. https://doi.org/10. 1016/j.crad.2017.05.003 [published Online First: 2017/06/09]

13. Tamai H, Takiguchi Y, Oka M et al (2005) Contrast-enhanced ultrasonography in the diagnosis of solid renal tumors. J Ultrasound Med 24(12):1635-1640 [published Online First: 2005/11/23]

14. Raman SP, Johnson PT, Allaf ME et al (2013) Chromophobe renal cell carcinoma: multiphase MDCT enhancement patterns and morphologic features. AJR Am J Roentgenol 201(6):1268-1276. https://doi.org/10.2214/ AJR.13.10813 [published Online First: 2013/11/23]

15. Muselaers $\mathrm{CH}$, Boerman OC, Oosterwijk E et al (2013) Indium-111-labeled girentuximab immunoSPECT as a diagnostic tool in clear cell renal cell carcinoma. Eur Urol 63(6):1101-1106. https://doi.org/10.1016/j.eururo.2013. 02.022 [published Online First: 2013/03/05]

16. Kay FU, Pedrosa I (2017) Imaging of Solid Renal Masses. Radiol Clin North Am 55(2):243-258. https://doi.org/10.1016/j.rcl.2016.10.003 [published Online First: 2017/01/28]

17. Froemming A, Potretzke T, Takahashi $\mathrm{N}$ et al (2018) Upper tract urothelial cancer. Eur J Radiol 98:50-60. https://doi.org/10.1016/j.ejrad.2017.10.021 [published Online First: 2017/12/28]

18. Browne RF, Meehan CP, Colville J et al (2005) Transitional cell carcinoma of the upper urinary tract: spectrum of imaging findings. Radiographics 25(6): 1609-1627. https://doi.org/10.1148/rg.256045517 [published Online First: 2005/11/15]

19. Vikram R, Sandler CM, Ng CS (2009) Imaging and staging of transitional cell carcinoma: part 2, upper urinary tract. AJR Am J Roentgenol 192(6):1488-1493. https://doi.org/10.2214/AJR.09.2577 [published Online First: 2009/05/22]

20. Takeuchi M, Konrad AJ, Kawashima A et al (2015) CT urography for diagnosis of upper urinary tract urothelial carcinoma: are both nephrographic and excretory phases necessary? AJR Am J Roentgenol 205(3):W320-W327. https://doi.org/10.2214/AJR.14.14075 [published Online First: 2015/08/22]

21. Potenta SE, D'Agostino R, Sternberg KM et al (2015) CT urography for evaluation of the ureter. Radiographics 35(3):709-726. https://doi.org/10. 1148/rg.2015140209 [published Online First: 2015/03/31]

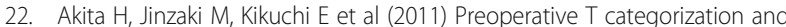
prediction of histopathologic grading of urothelial carcinoma in renal pelvis using diffusion-weighted MRI. AJR Am J Roentgenol 197(5):1130-1136. https://doi.org/10.2214/AJR.10.6299 [published Online First: 2011/10/25]

23. Chung AD, Schieda N, Shanbhogue AK et al (2016) MRI evaluation of the urothelial tract: pitfalls and solutions. AJR Am J Roentgenol 207(6): W108-WW16. https://doi.org/10.2214/AJR.16.16348 [published Online First: 2016/09/10]

24. Sobin L, Gospodarowicz M, Wittekind C (2010) TNM classification of malignant tumours. Urological Tumours. Renal Pelvis and Ureter. 7th revised edn. England: Wiley-Blackwell, UICC, pp 258-61. https://www.ncbi.nlm.nih. gov/nlmcatalog/101511218.

25. Sandrasegaran K, Menias CO, Verma S et al (2016) Imaging features of haematological malignancies of kidneys. Clin Radiol 71(3):195-202. https:// doi.org/10.1016/j.crad.2015.11.007 [published Online First: 2015/12/22]

26. Ganeshan D, lyer R, Devine C et al (2013) Imaging of primary and secondary renal lymphoma. AJR Am J Roentgenol 201(5):W712-W719. https://doi.org/ 10.2214/AJR.13.10669 [published Online First: 2013/10/24]

27. Sheth S, Ali S, Fishman E (2006) Imaging of renal lymphoma: patterns of disease with pathologic correlation. Radiographics 26(4):1151-1168. https:// doi.org/10.1148/rg.264055125 [published Online First: 2006/07/18]

28. Nicolau C, Sala E, Kumar A et al (2017) Renal masses detected on FDG PET/ $\mathrm{CT}$ in patients with lymphoma: imaging features differentiating primary renal cell carcinomas from renal lymphomatous involvement. AJR Am J Roentgenol 208(4):849-853. https://doi.org/10.2214/AJR.16.17133 [published Online First: 2017/01/18]

29. Katabathina $V$, Menias CO, Pickhardt P et al (2016) Complications of immunosuppressive therapy in solid organ transplantation. Radiol Clin North Am 54(2):303-319. https://doi.org/10.1016/j.rcl.2015.09.009 [published Online First: 2016/02/21]

30. Camacho JC, Moreno CC, Harri PA et al (2014) Posttransplantation lymphoproliferative disease: proposed imaging classification. Radiographics 34(7):2025-2038. https://doi.org/10.1148/rg.347130130 [published Online First: 2014/11/11]

31. Wu AJ, Mehra R, Hafez K et al (2015) Metastases to the kidney: clinicopathological study of 43 cases with an emphasis on deceptive features. Histopathology 66(4):587-597. https://doi.org/10.1111/his.12524 [published Online First: 2014/11/20]

32. Sanchez-Ortiz RF, Madsen LT, Bermejo CE et al (2004) A renal mass in the setting of a nonrenal malignancy: When is a renal tumor biopsy appropriate? Cancer 101(10):2195-2201. https://doi.org/10.1002/cncr.20638 [published Online First: 2004/10/08]

33. Adamy A, Von Bodman C, Ghoneim T et al (2011) Solitary, isolated metastatic disease to the kidney: Memorial Sloan-Kettering Cancer Center experience. BJU Int 108(3):338-342. https://doi.org/10.1111/j.1464-410X.2010. 09771.x [published Online First: 2010/11/19]

34. Bailey JE, Roubidoux MA, Dunnick NR (1998) Secondary renal neoplasms. Abdom Imaging 23(3):266-274 [published Online First: 1998/05/16]

35. Jinzaki M, Silverman SG, Akita $\mathrm{H}$ et al (2014) Renal angiomyolipoma: a radiological classification and update on recent developments in diagnosis and management. Abdom Imaging 39(3):588-604. https://doi.org/10.1007/ s00261-014-0083-3 [published Online First: 2014/02/08]

36. Park BK (2017) Renal Angiomyolipoma: radiologic classification and imaging features according to the amount of fat. AJR Am J Roentgenol 209(4):826-835. https://doi.org/10.2214/AJR.17.17973 [published Online First: 2017/07/21]

37. Flum AS, Hamoui N, Said MA et al (2016) Update on the Diagnosis and Management of Renal Angiomyolipoma. J Urol 195(4 Pt 1):834-846. https:// doi.org/10.1016/j.juro.2015.07.126 [published Online First: 2015/11/28]

38. Ishigami K, Jones AR, Dahmoush L et al (2015) Imaging spectrum of renal oncocytomas: a pictorial review with pathologic correlation. Insights Imaging 6(1):53-64. https://doi.org/10.1007/s13244-014-0373-x [published Online First: 2014/12/17]

39. Romis L, Cindolo L, Patard JJ et al (2004) Frequency, clinical presentation and evolution of renal oncocytomas: multicentric experience from a European database. Eur Urol 45(1):53-57 discussion 57. [published Online First: 2003/12/12]

40. Wobker SE, Williamson SR (2017) Modern pathologic diagnosis of renal oncocytoma. J Kidney Cancer VHL 4(4):1-12. https://doi.org/10.15586/jkcvhl. 2017.96 [published Online First: 2017/11/02]

41. Rosenkrantz AB, Hindman N, Fitzgerald EF et al (2010) MRI features of renal oncocytoma and chromophobe renal cell carcinoma. AJR Am J Roentgenol 195(6):W421-W427. https://doi.org/10.2214/AJR.10.4718 [published Online First: 2010/11/26]

42. Sasaguri K, Takahashi N, Gomez-Cardona D et al (2015) Small $(<4 \mathrm{~cm}$ ) renal mass: differentiation of oncocytoma from renal cell carcinoma on biphasic contrast-enhanced CT. AJR Am J Roentgenol 205(5):999-1007. https://doi. org/10.2214/AJR.14.13966 [published Online First: 2015/10/27]

43. Kim Jl, Cho JY, Moon KC et al (2009) Segmental enhancement inversion at biphasic multidetector $\mathrm{CT}$ : characteristic finding of small renal oncocytoma. Radiology 252(2):441-448. https://doi.org/10.1148/radiol.2522081180 [published Online First: 2009/06/11]

44. Gorin MA, Rowe SP, Baras AS et al (2016) Prospective evaluation of $(99 \mathrm{~m}) \mathrm{Tc}$ sestamibi SPECT/CT for the diagnosis of renal oncocytomas and hybrid oncocytic/chromophobe tumors. Eur Urol 69(3):413-416. https://doi.org/10. 1016/j.eururo.2015.08.056 [published Online First: 2015/09/21]

45. Tzortzakakis A, Gustafsson O, Karlsson M et al (2017) Visual evaluation and differentiation of renal oncocytomas from renal cell carcinomas by means of (99m)Tc-sestamibi SPECT/CT. EJNMMI Res 7(1):29. https://doi.org/10.1186/ s13550-017-0278-z [published Online First: 2017/03/31]

46. Das CJ, Ahmad Z, Sharma S et al (2014) Multimodality imaging of renal inflammatory lesions. World J Radiol 6(11):865-873 [published Online First: 2014/11/29]

47. Craig WD, Wagner BJ, Travis MD (2008) Pyelonephritis: radiologic-pathologic review. Radiographics 28(1):255-277. https://doi.org/10.1148/rg.281075171 quiz 327-8. [published Online First: 2008/01/22]

48. Ballard DH, De Alba L, Migliaro M et al (2017) CT imaging spectrum of infiltrative renal diseases. Abdom Radiol (NY) 42(11):2700-2709. https://doi.org/10.1007/s00261-017-1193-5 [published Online First: 2017/06/06]

49. Loffroy R, Guiu B, Watfa J et al (2007) Xanthogranulomatous pyelonephritis in adults: clinical and radiological findings in diffuse and focal forms. Clin Radiol 62(9):884-890. https://doi.org/10.1016/j.crad.2007.04.008 [published Online First: 2007/07/31]

50. Daher Ede F, da Silva GB, Jr., Barros EJ. (2013) Renal tuberculosis in the modern era. Am J Trop Med Hyg 88(1):54-64. https://doi.org/10.4269/ajtmh. 2013.12-0413 [published Online First: 2013/01/11] 
51. Kauffman CA, Fisher JF, Sobel JD et al (2011) Candida urinary tract infections-diagnosis. Clin Infect Dis 52(Suppl 6):S452-S456. https://doi.org/ 10.1093/cid/cir111 [published Online First: 2011/04/22]

52. Bhatt S, MacLennan G, Dogra V (2007) Renal pseudotumors. AJR Am J Roentgenol 188(5):1380-1387. https://doi.org/10.2214/AJR.06.0920 [published Online First: 2007/04/24]

53. Palmucci S, Torrisi SE, Caltabiano DC et al (2016) Clinical and radiological features of extra-pulmonary sarcoidosis: a pictorial essay. Insights Imaging 7(4):571-587. https://doi.org/10.1007/s13244-016-0495-4 [published Online First: 2016/05/26]

54. lannuzzi MC, Rybicki BA, Teirstein AS (2007) Sarcoidosis. N Engl J Med 357(21):2153-2165. https://doi.org/10.1056/NEJMra071714 [published Online First: 2007/11/23]

55. Roudenko A, Murillo P, Akers S et al (2012) Renal sarcoid: pseudotumoral radiologic manifestations and pathologic correlation. Radiol Case Rep 7(2): 599. https://doi.org/10.2484/rcr.v7i2.599 [published Online First: 2012/01/01]

56. Heldmann M, Behm W, Reddy MP et al (2005) Pseudotumoral renal sarcoid: MRI, PET, and MDCT appearance with pathologic correlation. AJR Am J Roentgenol 185(3):697-699. https://doi.org/10.2214/ajr.185.3.01850697 [published Online First: 2005/08/27]

57. Goldsmith S, Harris M, Scherer K et al (2013) Sarcoidosis manifesting as a pseudotumorous renal mass. J Radiol Case Rep 7(5):23-34. https://doi.org/ 10.3941/jrcr.v7i5.1316 [published Online First: 2013/05/25]

58. Martinez-de-Alegria A, Baleato-Gonzalez S, Garcia-Figueiras R et al (2015) IgG4-related disease from head to toe. Radiographics 35(7):2007-2025. https://doi.org/10.1148/rg.357150066 [published Online First: 2015/10/17]

59. Ono H, Murakami T, Mima A et al (2017) Successful treatment of highly advanced immunoglobulin G4-related kidney disease presenting renal mass-like regions with end-stage kidney failure: a case study. BMC Nephrol 18(1):261. https://doi.org/10.1186/s12882-017-0676-5 [published Online First: 2017/08/05]

60. Seo N, Kim JH, Byun JH et al (2015) Immunoglobulin G4-related kidney disease: a comprehensive pictorial review of the imaging spectrum, mimickers, and clinicopathological characteristics. Korean J Radiol 16(5): 1056-1067. https://doi.org/10.3348/kjr.2015.16.5.1056 [published Online First: 2015/09/12]

61. Tang CSW, Sivarasan N, Griffin N (2018) Abdominal manifestations of IgG4related disease: a pictorial review. Insights Imaging 9(4):437-448. https://doi. org/10.1007/s13244-018-0618-1 [published Online First: 2018/04/27]

62. Hedgire SS, McDermott S, Borczuk D et al (2013) The spectrum of IgG4related disease in the abdomen and pelvis. AJR Am J Roentgenol 201(1):1422. https://doi.org/10.2214/AJR.12.9995 [published Online First: 2013/06/26]

63. Faucon AL, Bobrie G, Jannot AS et al (2018) Cause of renal infarction: a retrospective analysis of 186 consecutive cases. J Hypertens 36(3):634-640. https:// doi.org/10.1097/HJH.00000000000001588 [published Online First: 2017/10/19]

64. Suzer O, Shirkhoda A, Jafri SZ et al (2002) CT features of renal infarction. Eur J Radiol 44(1):59-64 [published Online First: 2002/09/28]

65. Kawashima A, Sandler CM, Ernst RD et al (2000) CT evaluation of renovascular disease. Radiographics 20(5):1321-1340. https://doi.org/10. 1148/radiographics.20.5.g00se141321 [published Online First: 2000/09/19]

66. Tenant SC, Gutteridge CM (2016) The clinical use of contrast-enhanced ultrasound in the kidney. Ultrasound 24(2):94-103. https://doi.org/10.1177/ 1742271X15627185 [published Online First: 2016/08/03]

67. Osako Y, Tatarano S, Nishiyama K et al (2011) Unusual presentation of intraparenchymal renal artery aneurysm mimicking cystic renal cell carcinoma: a case report. Int J Urol 18(7):533-535. https://doi.org/10.1111/j. 1442-2042.2011.02775.x [published Online First: 2011/05/17]

68. Coleman DM, Stanley JC (2015) Renal artery aneurysms. J Vasc Surg 62(3):779785. https://doi.org/10.1016/j.jvs.2015.05.034 [published Online First: 2015/07/28]

69. Vitale V, Di Serafino M, Vallone G (2013) Renal artery aneurysm mimicking a solid parenchymal lesion. J Ultrasound 16(3):131-134. https://doi.org/10. 1007/s40477-013-0021-1 [published Online First: 2014/01/17]

70. Silverman SG, Mortele KJ, Tuncali K et al (2007) Hyperattenuating renal masses: etiologies, pathogenesis, and imaging evaluation. Radiographics 27(4):11311143. https://doi.org/10.1148/rg.274065147 [published Online First: 2007/07/11]

71. Siddaiah M, Krishna S, McInnes MDF et al (2017) Is ultrasound useful for further evaluation of homogeneously hyperattenuating renal lesions detected on CT? AJR Am J Roentgenol 209(3):604-610. https://doi.org/10. 2214/AJR.17.17814 [published Online First: 2017/07/06]

72. Kim CW, Shanbhogue KP, Schreiber-Zinaman J et al (2017) Visual assessment of the intensity and pattern of T1 hyperintensity on MRI to differentiate hemorrhagic renal cysts from renal cell carcinoma. AJR Am J Roentgenol 208(2):337-342. https://doi.org/10.2214/AJR.16.16710 [published Online First: 2016/11/16]

73. Agnello F, Albano D, Micci G et al (2020) CT and MRI imaging of cystic renal lesions. Insights Imaging 11(5). https://doi.org/10.1186/s13244-019-0826-3 [published Online First: 2020/01/03]

74. Mazziotti S, Cicero G, D'Angelo T et al (2017) Imaging and management of incidental renal lesions. Biomed Res Int 2017:1854027. https://doi.org/10. 1155/2017/1854027 [published Online First: 2017/06/24]

75. Algin O, Ozmen E, Gumus M (2014) Hypertrophic columns of bertin: imaging findings. Eurasian J Med 46(1):61-63. https://doi.org/10.5152/eajm. 2014.12 [published Online First: 2015/01/23]

76. Stine VE, Wolfman NT, Dyer RB (2015) The "dromedary hump" appearance. Abdom Imaging 40(8):3346-3347. https://doi.org/10.1007/s00261-015-05167 [published Online First: 2015/08/01]

77. Wang ZJ, Nikolaidis P, Khatri G et al (2020) ACR Appropriateness criteria ${ }^{\odot}$ indeterminate renal mass. JACR 17(11):S415-S428. https://doi.org/10.1016/j. jacr.2020.09.010 [published Online First 2020/11/01]

78. Sebastià C, Corominas D, Musquera M et al (2020) Active surveillance of small renal masses. Insights Imaging 11(1):63. https://doi.org/10.1186/ s13244-020-00853-y [published Online First 2020/05/05]

79. Lim CS, Schieda N, Silverman SG (2019) Update on indications for percutaneous renal mass biopsy in the era of advanced CT and MRI. AJR Am J Roentgenol:1-10. https://doi.org/10.2214/AJR.19.21093 [published Online First 2019/03/27]

80. Meyer M, Nelson RC, Vernuccio F et al (2019) Virtual unenhanced images at dualenergy CT: influence on renal lesion characterization. Radiology 291(2):381-390. https://doi.org/10.1148/radiol.2019181100 [published Online First 2019/03/12]

81. Sistani G, Romsa J, Stephen P et al (2020) 99mTC-Sestamibi SPECT/CT imaging for the risk stratification of renal masses. J Nucl Med 61(supplement 1):1586-1586 [published Online First 2020/05/01]

\section{Publisher's Note}

Springer Nature remains neutral with regard to jurisdictional claims in published maps and institutional affiliations.

\section{Submit your manuscript to a SpringerOpen ${ }^{\circ}$ journal and benefit from:}

- Convenient online submission

- Rigorous peer review

- Open access: articles freely available online

High visibility within the field

- Retaining the copyright to your article

Submit your next manuscript at $>$ springeropen.com 